\title{
Assessing the compliance of architectural design of social housing models in new cities with social needs of relevant residents
}

\author{
Case study (The social housing project, New El-Minya City)
}

\author{
Ashraf A. Abd Al-Raheem ${ }^{1} \quad$ Najat A. Makhlouf ${ }^{2} \quad$ Medhat M. A. Osman ${ }^{3}$ \\ ${ }^{1}$ Associated professor, Architecture Dept., Faculty of engineering, Minia university, Egypt \\ ${ }^{2}$ MSc. Student, Architecture Dept., Faculty of engineering, Minia university, Egypt \\ ${ }^{3}$ Assistant professor, Architecture Dept., Faculty of engineering, Minia university, Egypt \\ *Corresponding author Email: medhat.osman@mu.edu.eg
}

\begin{abstract}
: -
This paper studies, analyzes and evaluates the architectural design of social housing models in Egyptian new cities in terms of the availability of social needs along with their compliance with residents' own needs. Social needs under investigation are the need for communication, privacy, containment, protection, symbolism, functionality, and personality achievement. The main concern of research is to introduce a quantitative index expresses the degree of compliance of such needs with desires of the low-income social class targeted to reside in such projects. The research methodology combined three major methods to measure compliance between requirements of such class and the architectural design of the project through employing specific social class and their housing project within New El-Minya City as a case study. First, a theoretical analysis of the case study housing model design along with its urban context is conducted. Also, assessment, analysis, and observation by photography are used to specify modifications made by residents to their residential units to fit their social needs. Finally, structured interviews are conducted with people from the social class targeted to be accommodated in such residential models in New El-Minya City. The interviews aimed to measure their priorities in terms of social needs and the needs' achievable design features. The interviews then analyzed by transforming the qualitative data collected from the sample into quantitative data to identify merits and demerits of design in terms of meeting the different social needs of this class expressed by a specific quantitative number. Results of applying these methods showed random modifications made by residents to compensate their missing requirements. The proposed quantitative index's results showed a huge design deficiency in meeting the social requirements of residents. The case study design matches the social needs of residents' social class by only $(50.3 \%)$. This was referred to miss communication between designers and users in early design stage. In addition, the wrong policy of adoption of a single housing model to be built all over the country without taking into consideration the different social priorities and needs of the same social class in different communities.
\end{abstract}

Keywords: Architectural design, Social housing, Residents' social needs, Egyptian community. 


\section{تقييم مدى توافق التصميم المعماري لنماذج الإسكان الاجتماعي الحكومي بالمدن الجديدة

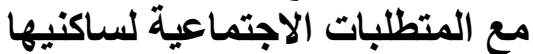 \\ دراسة حالة (مشروع الإسكان الاجتماعي بمدينة المنيا الجديدة) \\ د.م مدحت محمد أحمد عثمان

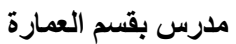 \\ كلية الهندسة ـ جامعة المنيا

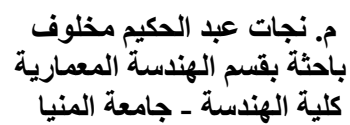

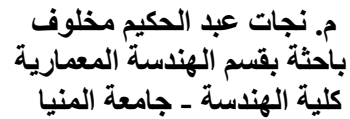 \\ أ.م.د. أشرف ابو العيون عبد الرحيم \\ أستاذ مساعد بقسم العمارة \\ كلية الهندسة - جامعة المنيا}

*Corresponding author Email: medhat.osman@mu.edu.eg

ملخص البحث:

تتناول هذه الورقة البحثية در اسة وتحليل وتقييم التصميم المعماري لنماذج الإسكان الاجتماعي الحكومي بالمدن الجديدة في مصر من حيث توافر المنطلبات الإجتماعية كالحاجة إلى الإتصال و الخصوصية والاحتواء و الحماية والرمزية والوظيفية وتحقيق الثخصية ومدي تو افق درجة تحقق تلك المتطلبات مع رغبات الثريحة الإجتماعية المستهدف تسكينها بتلك المشرو عات. وقد إتخذ البحث أحد مشرو عات الإسكان الإجتماعي بمدينة المنيا الجديدة مع الثريحة الإجتماعية المستهدفة بمثل هذه المشرو عات كحالة در اسة. وقد إعتمد البحث في منهجيته على محاور رئيسية ثلاثة لقياس مدي التوافق بين منطلبات تللك الطبقة الإجتماعية والتصميم المعماري لهذا المشروع، وذلك من خلال التحليل النظري للنموذج السكنى المستخدم والموقع العام، كما إتبع البحث أسلوب التقبيم و التحليل و الرصد من خلال التصوير لتحديد ما قام به السكان من إدخال تعديلات على وحداتهم السكنية لكى تتو ائم مع إحتياجاتهم ومتطلباتهم الاجتماعية ، و أخيراً عمل مقابلات بأسئلة معدة مسبقاً مع فئات السكان المستهدف تسكينهم بتلك النماذج السكنية بمدينة المنيا الجديدة كمحاولة لإشر اكهم كمستخدمين في التقييم ولتحديد وقياس أولويات متطلباتهم بتحويل البيانات النوعية المجمعة من عينة الدر اسة لبيانات كمية بهدف التوصل الى تحديد أوجه القصور و النجاح في أسلوب تصميم تلك النماذج من حيث تحقيقها للمتطلبات الإجتماعية المختلفة لتلك الثريحة الإجتماعية معبراً عنه برقم حسابي كمي. و أفرزت نتائج تطبيق تلك المنهجيات وجود تعديلات عشو ائية للسكان بالتصميم لتعويض قصور في بعض متطلباتهم، وكذا أمكن الحكم بأن تصميم حالة الدر اسة متو افق بنسبة ؟, ـ0 \% مع المتطلبات الإجتماعية للسكان من تلك الثريحة الإجتماعية، وأن التصميم يوجد به قصور كبير في تحقيق المنطلبات الإجتماعية للسكان، و أرجع البحث ذلك لغياب التواصل بين المصمم و المستخدم وتصميم نموذج موحد ينفذ في جميع أنحاء البلاد بدون الأخذ في الإعتبار إختلاف أولويات ومتطلبات السكان الإجتماعية لنفس الطبقة بإختلاف بيئاتهم الإجتماعية.

$$
\text { الكلمات الدالة: التصديم الدعماري، الإسكان الإجتماعي، الإحتياجات الإجتماعية للسكان، الدجتمع الدصري. }
$$




\section{Journal of Advanced Engineering Trends (JAET), Vol. 38, No. 2. July}

دراسة وتحليل حالة الدراسة وذللك لأحد نماذج الإسكان الإجتماعي الحكومي بمدينة المنيا الجديدة وذللك لتقييم الوضع الحالي للمباني السكنية في المدن الجديدة من حيث تلبيتها لر غبات السكان و إحتياجاتهم.

؛. المتطلبات الاجتماعية الواجب تو افرها في المباني السكنية :(Social Needs in Residential Buildings)

يمكن تعريف الإحتياجات و المتطلبات الإجتماعية على أنها الرغبات أو الأحلام التى يمكن بتو اجدها أن تحقق راحة الفرد. وفى مجال العمران يمكن أن تتحول تللك الإحتياجات بواسطة

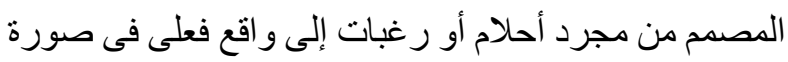
مادية أو معنوية [']. ويعريف الإحتياج بأنه "القوى الدافعة للإنسان فى تشكيل وتغبير بيئته العدر/نية" [؟]. وتنزايد

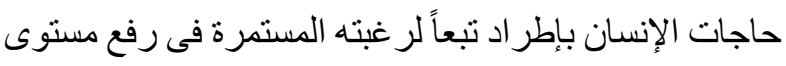
معيشته ومحاولته الدائمة لإستغلال ما وهبه الله لتحقيق تلك لتك الإحتياجات، و عند تحقيقها تبدأ دورة طموح جديدة للإنسان بتطلع خلالها إلى تحسين وضعه ورفع مستوى معيشته فتتغير بذللك تطلحاته ومن ثم إحتياجاته و هكذا إلى ما شاء الله. وحيث أن متطلبات الإنسان الإجتماعية تعنى إنتمائه الإجتماعى لأسرته وجماعته وقبيلته ومؤسسته ومدينته ومجتمعه الكبير أياً كان، وتتكون تللك المتطلبات بين الأفر اد نتيجة وجودهم فى ونى مجتمع واحد حيث تتبادل خلالهم المنفعة فى دفع الضرر عن بعضهم البعض ونواجد صلات التراحم و التواصى بالخير طبقا لما تشير اليه القيم الإجتماعية والعقائد الدينية التى تحددها

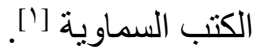

وتختلف الإحتياجات الإجتماعية من مجتمع لأخر نتيجة لإختلاف الأنماط السلوكية ويدخل فى الإعتبار ميول الأفراد ورغباتهم، حيث أن الإنسان يعيش طبقاً لحدود إجتماعية ترسمها له الثقافة السائدة فى المجتمع، وهو بذللك يتأثر بالدو افع إنع و القيود الإجتماعية السائدة ومظاهر العرف و التقاليد
1. مقدمة البحث (Research Introduction): مما لا شك فيه أن عملية التقييم من العمليات المهمة التي تحدد إيجابيات وسلبيات أي عمل، و التي تساعد متخذي القرار على التعرف على بعض المشاكل الناتجة عن إهمال بعض العو امل التي يجب العمل بها وبالتالي يتم تعديلها لتحقيق أكبر استفادة مككنة وتحقيق أكبر عدد من الأهداف المرجوة. وقد تناولت هذه الورقة البحثية تقييم أحد نماذج الاسكان الاجتماعي الحكومي في مدينة المنيا الجديدة من حيث تقدير توفر المنطلبات الاجتماعية بها بشكل كمي، مع إلقاء الضوء على بعض الجوانب التي قد يكون أهملها المصمم و التي لها أهمية عند المستخدم المنتمي للشريحة الإجتماعية المخاطبة بتلك

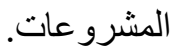

$$
\begin{aligned}
& \text { ץ. أهداف البحث (Research Aims): } \\
& \text { يهدف البحث إلي: }
\end{aligned}
$$

• در اسة المنطلبات الاجتماعية الواجب نو افرها في تصميم المباني السكنية، • تقييم وتحليل أحد نماذج الإسكان الاجتماعي الحكومي المستخدمة في المدن الجديدة و التحديد الكمي لمدى وملاءمتها لمتطلبات الشريحة الإجتماعية المستهدفة للسكان وأوجه القصور في تصميمها.

\section{r. منهجية البحث (Research Methodology):}

تحقيقاً لأهداف البحث، فقد إرنكزت منهجية البحث على الدراسة النظرية وتأكيدها بالو اقع العملي وذلك من خلال الجمع بين المنهج الاستقرائي النظري، والمنهج النطبيقي التحليلي لدراسة وتحليل وتقييم حالة الدراسة. إعتمد المنهج الاستقرائي النظري على مر اجعة الأدبيات والدوريات العلمية لإسنتباط المنطلبات الإجتماعية و المعايير التصميمية لتحقيقها في المباني السكنية، واعتمد المنهج التطبيقي التحليلي على 


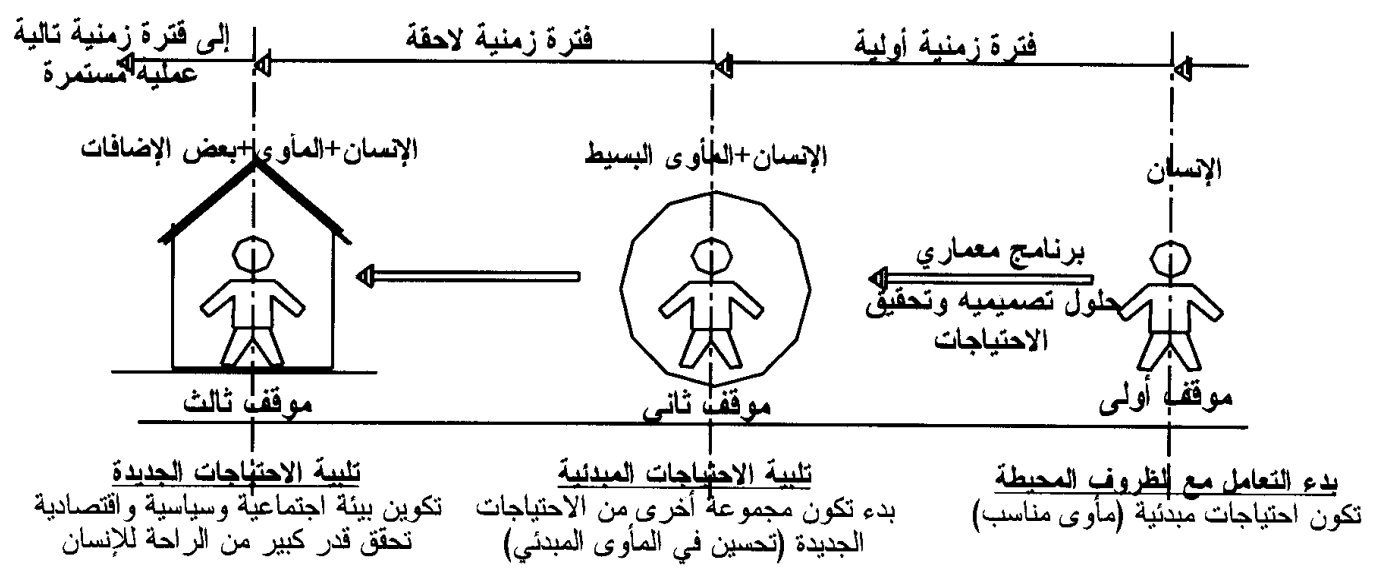

شكل (1): دورة الإحتياج وطموح الإنسان فى ضوء المفهوم العام للإحتياجات [']

وتعتبر أهم الاحتياجات المعبرة عن مفردات التواصل الاجتماعى هى الحاجة الى المعاملات و الحاجة الى الإنتماء وتكوين العلاقات الإجتماعية والتعاون و المشاركة و الحاجة الى حسن الجوار والحاجة لتكوين الخبرات، وتعتبر أهم المعايير التصميمية المعمارية اللازمة لتحقيق الحاجة الى

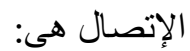
• توفير البيئة المهيأة لإلتقاء الناس على مستوى الأفراد و الجماعات وتضم هذه الوسائل الأماكن الخاصة بالحركة

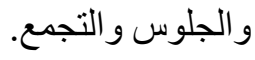
• تهيئة المساحات والحيزات الثبه خاصة مثل الثرفات و الأسطح و الحدائق الخارجية للمبني السكني للجلوس

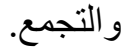
• إستخدام الفر اغات العمر انية المتصلة.

ع. ץ الحاجة للخصوصية (The Need to Privacy): و هي من أهم الحاجات الإجتماعية للإنسان والتى تحقق له قدرا" من الراحة النفسية. وتلعب الخصوصية دوراً هاماً وحيوياً فى حياة الإنسان وتمثل جزء لا ينفصل عن عاداته وتقاليده وثقافته. كما يرى بعض الباحثين أن الخصوصية كجزء من الحاجات الأمنية (الحماية من تبصص الآخرين) والتي تأتى ضمن هرم ماسلو فى الترتيب الثانى لاحتياجات
الإجتماعية المميزة لمجتمعه [־]ـ. ويوضح الثكل رقم (1) تطور الإحتياجات مع تطور فكر الإنسان ودورة طموحه فى لئ ضوء المفهوم العام للإحتياجات الإجتماعية الموضح سابقاً. ويمكن تلخيص المنطلبات الإجتماعية المطلوب توافرها فى المبانى السكنية من و اقع المر اجعة النظرية لأدبيات الموضوع و الدر اسات السابقة فيما يلي.

ع. 1 الحاجة للمعيشة فى جماعة (الحاجة للاتصال) :(The Need to Social Communication)

الإنسان فى حاجة مستمرة للمعيشة فى مجمو عة متآلفة لديهم الثعور بالإنتماء لمجتمع محيط فلا يستطيع الإنسان أن يعيش منفرداً بدون علاقات إجتماعية وجير ان ومعاملات ومشاركة وجدانية أو فعالة فى إهتمامات تللك الجماعة حتى تتكون لديه الخبرات الحياتية اللازمة لإستمرار حياته ودعم سلوكه وتصرفاته فى المو اقف المختلفة، ومن المسلم به أن الوصول إلى الإتزان النفسي للإنسان يتطلب أن يكون عضواً فى مجمو عة فيها الأصغر منه وفيها الأكبر وأن يكون له تطلعاته للصعود لأعلى درجات السلم الإجتماعى إذ أن تللك الطموحات تعتبر الدافع النفسى له للعمل والاستزادة من الثقافة والعلم و التقدم لكي يرتفع بمكانته الاجتماعية بين أقر انه فهو إذا فقد هذا الطموح فقد دافعه للحياه [ـ]. 
الإحتواء و أهميته للإنسان فإنه يمكن وصفه بأنه محاولة إقتطاع حجم محدد من الوسط البيئى الطبيعى المحيط وتشكيله

جدول (1) : أهم المعايير التصميمية المعمارية الواجب توافرها في المبنى المئى

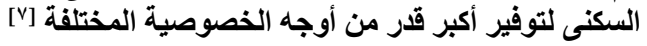

\begin{tabular}{|c|c|}
\hline 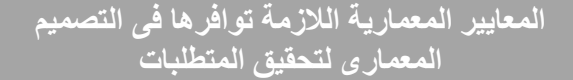 & الإجتماعي \\
\hline 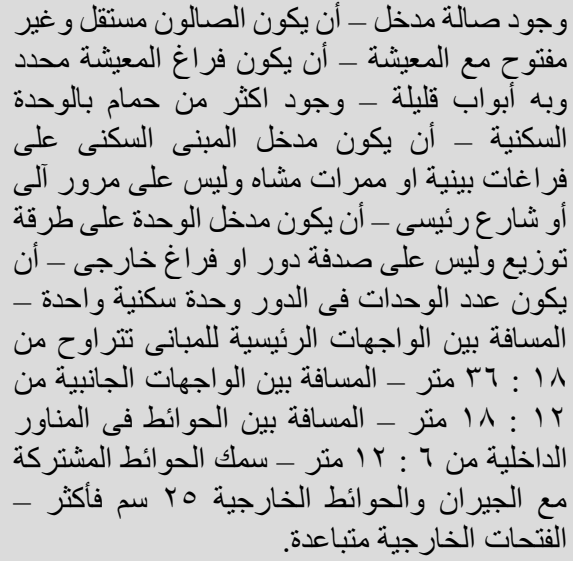 & الخصوصبية \\
\hline
\end{tabular}

وفقاً لإحتياجات البشر من السلام والهدوء و الإنتماء وخلق البيئة المناسبة لحياة ونشاط الكائن البشرى [^]ـ. ويتوقف التنأثير السيكولوجي للإحتواء على شكل الفراغ ونسبة والتي تخلق درجة معينة من الإحتو اء. ودرجات الإحتو اء تنقسم إلى: فراغ شديد الاحتواء، وفراغ متوسط الاحتواء، وفراغ ضعيف الاحتواء، وفر اغ منعدم الاحتو اء. حيث يعتمد تصنيف الفراغ من حيث درجة إحتواءه على النسبة بين العرض والإرتفاع وز اوية الرؤية [] كما هو موضح بالثكل رقم (r).

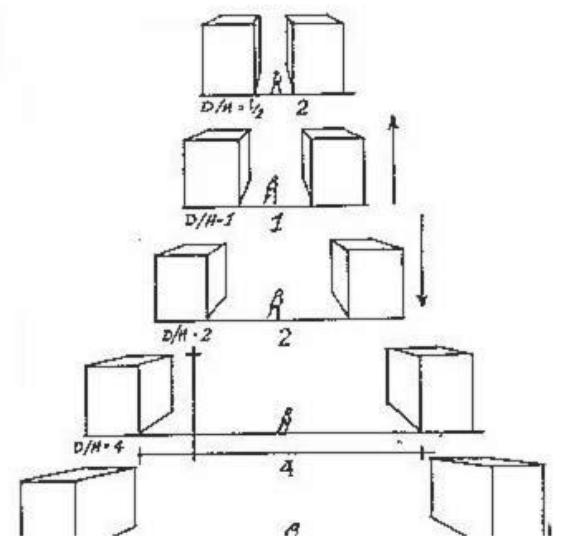

شكل ("r): نسب الفراغ ودرجات الإحتواء [9"]
الانسان بعد الاحتياجات الفسيولوجية مباشرة كما هو موضح

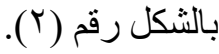

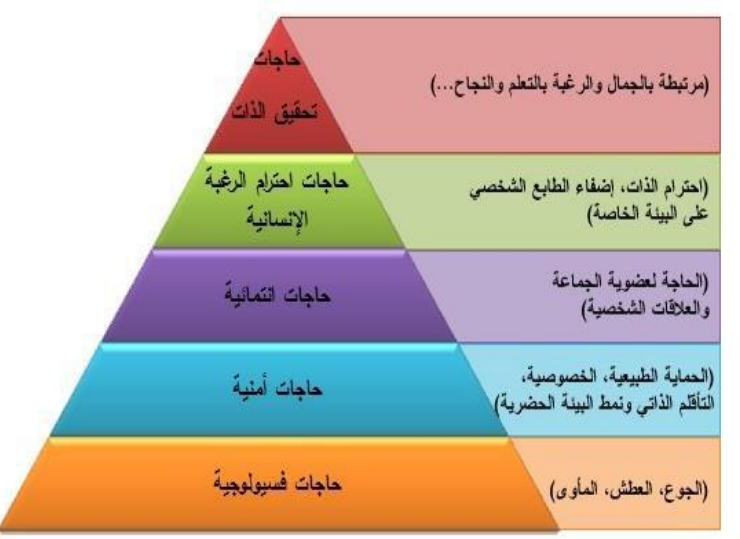

شكل (ץ): هرم ماسلو وموقع الخصوصية ضمن الإحتياجات الأمنية

مما يعني أن أى إنسان سيسعى بعد إثباع احتياجاته

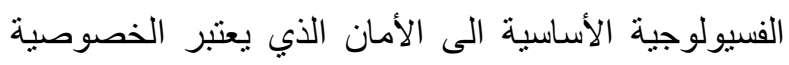

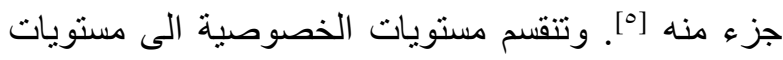
ثلاث مستويات هي الخصوصية علي المستوي العام والخصوصية علي المستوي شبه العام وعلي المستوي الخاص ["]، وتم حصر اوجه الخصوصية التى يحتاجها الإنسان ويمكن التحكم بدرجة تحققها معمارياً في كل من: الحاجة إلي الخصوصية البصرية، و الحاجة إلي الخصوصية السمعية، والحاجة الى الخصوصية الاجتماعية، و الحاجة الى إلى المحافظة على الحرية الثخصية، و الحاجة للانفر اد مع النفس. ويعرض جدول رقم (1) أهم المعايير التصميمية المعمارية الواجب تو افرها فى المبنى السكنى لتوفير أكبر قدر من أوجه الخصوصية المختلفة.

؛. ب الحاجة الى الاحتواء (The Need to Containment): و هو مطلب فطري لأي كائن حي، وأحد الشروط اللازمة لإستمر ار الحياة ومن خلال الإحتو اء يستطيع الفرد أن يمارس حياته بصورة خلاقة ومبدعة ومنظمة. ولتوضيح مفهوم 


\section{Journal of Advanced Engineering Trends (JAET), Vol. 38, No. 2. July}

ع. • الحاجة الى الرمزية (The Need to Symbolism):

و هي من الحاجات الإجتماعية الموجودة لدى كل بشرى وإن لم يكن يقصدها أو يسعى إليها فهي و اقع ملموس يحتل صورة و اقعية فى حياته تتكون نتيجة ثقافة معينة. "فالرمز هو وجود

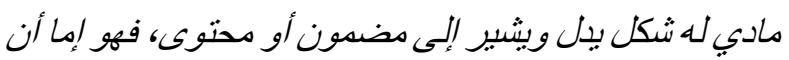
يكون شكلًً أو صورة ذات وجود قائم بذاته أو معنى لدلالة أو إثارة سواءً كان ذلك بالنسبة للفرد أو لمجتمع ما " [ـ "]. وفى تحليلنا للخصائص الإنسانية لمجتمع ما تظهر فيه أهمية الرمزية فإننا لا نستطيع فهم الممارسات المختلفة للإنسان فى أى ثقافة معينة بدون معرفة الدور الوسيط الذي تعبر عنه

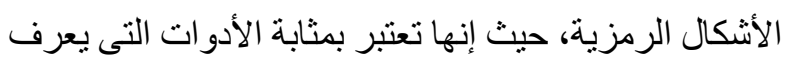
بها ثقافة الإنسان فالرموز تعد وسائل أساسية فى المعرفة ومن دونها تستحيل معرفة ثقافته. وتكون الأشكال الرمزية مجموع الثقافة بوصفها مؤسسة إنسانية خاصة وتللك الأشكال التي يمكن ملاحظتها فى اللغة و الدين و الأسطورة و الفن و المعرفة العلمية، هي بمثابة عناصر تحدد نسق الثقافة مما يفيد وجود علاقات وروابط فيما بينها، وبالتالي فإن الثقافة يتم التعبير عنها بمجموعة الأشكال الرمزية التى يبدعها الإنسان خلال

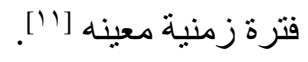

\section{צ. 7 الحاجة الى الوظيفية (The Need to Functionality):}

بعيدا عن الجدران الحاوية للسكن تظهر وظيفة السكن الأساسية في أنها تحوي وتجسد نشاطاً حيوياً في المقام الأول سواء على مستواه البسيط المتمنل في الاسترخاء و النوم أو علي مستويات أكثر تصاعداً وتعقيداً كتربية طفل وتجهيز الطعام و القر اءة. فالمسكن هو البيئة التي يعيش فيها الإنسان وتعتبر هذه البيئة هي من أهم الإحتياجات الإجتماعية الرئيسية للأسرة الصغيرة أو العائلة الممتدة أو الفرد. ووظيفة المسكن توفير الخصوصية وإحتواء الأنشطة الحيوية المختلفة التي يقوم بها الأفر اد من أنشطة معيشية وإجتماعية وثقافية و إنتاجية
وتتخلص أهم المعايير المعمارية اللازمة لتحقيق الإحتواء

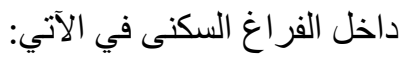

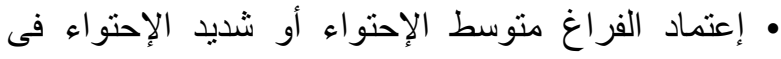
الفراغات العمرانية، أى أن تكون النسبة بين عرض الفراغ

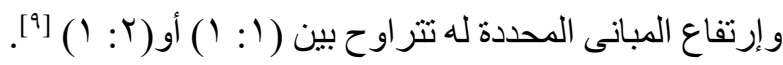
• زيادة محددات الفر اغ من عناصر نباتية أو أشجار وخلافه. • إستخدام الشكل المنتظم للفراغ.

؟. ؛ الحاجة الى الحماية (The Need to Be Protected): و هي إحساس الإنسان بالطمأنينة وهو شعور داخلى بالأمان مع نفسه وحياته وممتلكاته، وقد عرفها (ماسلو) [^] بأنها ذلك بلك الحاجز المادي الذى يفصل الإنسان عن المحيط الحيوي بقصد توفير منظومة لإحساس الفرد بالأمان و الطمأنينة، أو هى ذلك الشعور الداخلي بالأمن والأمان من كل القوى المحيطة. وتم حصر أوجه الحماية من المضار في الحماية ضد الاخطار، و الحماية ضد العدوى، وضرورة النظافة والصيانة، ونوفير إنارة كافية وشمس وتهوية كافيان، و الحماية ضد الضوضلاء، و الحماية ضد تلوث الهو اء، وكذا توفير الفرص لحماية العائلة و المجتمع وتوفير إمكانية الر احة أو الجمال. ويمكن تلخيص أهم المعايير التصميمية لتحقيق الحماية فيما يلي: • التدرج الهرمي للفر اغات العمر انية. • تجنب حركة السيار ات داخل الفراغ السكنى. • تجنب التلوث السمعي من الضوضاء و التلوث الهوائي من

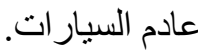
• أن يقع مدخل المبني السكني على ممرات مشاه أو فر اغات سكنية. • توفير سبل الحماية من أخطار الحريق ومنع انتشاره. • توفير منطقة لعب آمنة للأطفال وتكون معزولة عن الطر قات. 
• تحديد التجمعات السكنية وفراغاتها المختلفة لتكون خاصة

$$
\text { بساكنيها دون غير هم. }
$$

• أن يكون التصميم المعماري مرناً مما يتيح للساكن تغيير

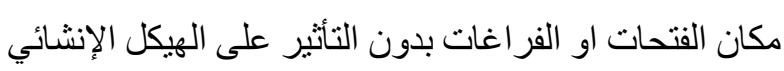

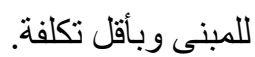

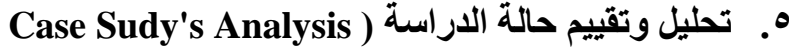
:(and Evaluation

يعرض هذا الجزء من البحث تفاصيل الدراسة التطبيقية

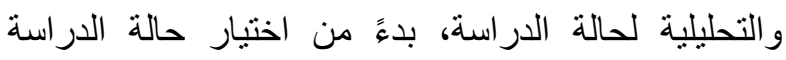
ووصفها، ومرور اً بالمنهجية التفصيلية لعملية التحليل و التقييم باستخدام الطرق البحثية المختلفة، وإنتهاءً بسرد ومناقشنة النتائج التي أفرزتها كل من الطرق البحثية المختلفة.

๑. 1 إختيار حالة الدراسة (Choosing Case Study): عمرانياً: تم إختيار مدينة المنيا الجديدة كأحد المدن الجديدة التى أقيمت فى الإقليم الصحراوي المصري حيث تقع في نطاق الصحر اء الشرقية وإلي جهة الثرق من مدينة المنيا القائمة بالو ادي (شكل رقم ع) لتكون حالة الدر اسة فى البحث وذلك لوجودها في النطاق الجغر افي لعمل الباحثين مما يسهل عملية الوصول إليهاوتطبيق الدراسة ومتابعتها. وتعتبر مدينة المنيا الجديدة من مدن الجيل الثانى، وتم إنشائها بقرار مجلس

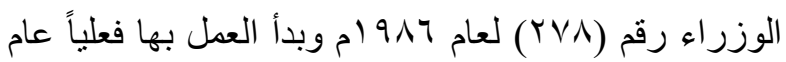
199 (م، وتنقسم كتلنها العمر انية الحالية إلي جزئين: الكتلة العمر انية الرئيسية وتتكون من عدد ستة أحياء سكنية و العديد من مشروعات الإسكان الإجتماعي بنسبة إثنغال عالية، ومنطقة الإمتداد والمكونة من أثنين من الاحياء السكنية مع مشرو عات الإسكان الإجتماعي الحالية وبنسبة إثغال ضعيفة. تم در اسة الأعداد المنفذة و الجاري تنفيذها من النماذج المختلفة للإسكان الإجتماعي الحكومي بمدينة المنيا الجديدة وتم إختيار نموذج حالة الدر اسة على أساس أنه الأحدث تصميماً و الأكثر
وترفيهية ودينية و أدائها بيسر [־']، ويمكن تلخيص أهم معايير

تحقيق الوظيفية بالجدول رقم (r).

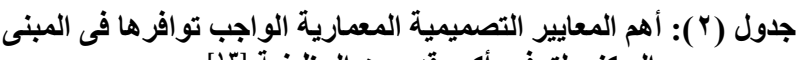

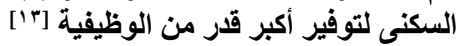

\begin{tabular}{|c|c|}
\hline 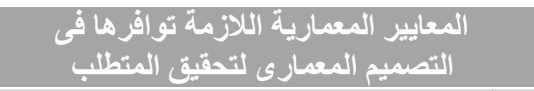 & الإمتماعي \\
\hline 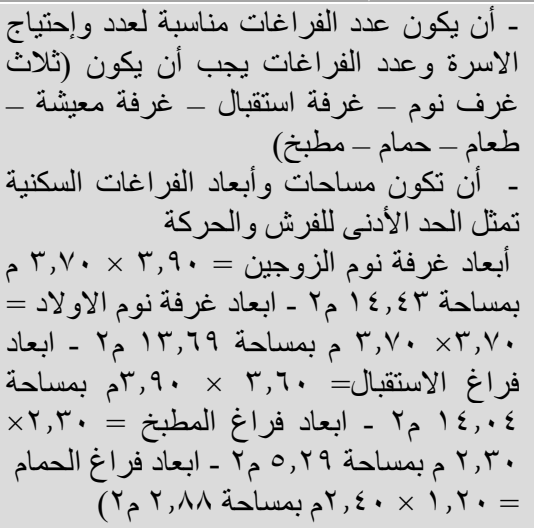 & الوظية:بة \\
\hline
\end{tabular}

The (الحاجة الى تحقيق الثخصية وخلق الفردية V Need to Achieve Personality and Create :(Individual Identity

و هي من أهم الإحتياجات الإجتماعية التى يسعى الإنسان لتحقيقها فى بيئته العمر انية، فهو يسعى دائماً لإضفاء شخصيته المميزة على المكان الذي يقطنه ووضع بصماته عليه مما يخلق نوعاً من الحدود يوحى للأخرين بيداية ونهاية المكان وحدود سيطرته ويقاس هذا ليس على مستوى الفرد فقط، ولكن على مستوى الجماعة أيضاً، وتم حصر أوجه تحقيق الشخصية وخلق الفردية التى يحتاجها الإنسان فى الحاجة الى الفاعلية و التأثير و الحاجة للملكية والحدود و الحاجة لإظهار الذات و الحاجة لتكوين بيئة خاصة و الحاجة الى الاحتر ام. وأهم المعايير المعمارية اللازمة لتحقيق الثخصية وخلق الفردية يمكن تحديدها فيما يلي: • تحديد الملكيات العامة و الخاصة. • أن يكون للمستخدمين دور ورأى فى التشطيب النهائي

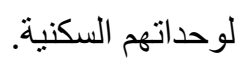


غرف ومطبخ وحمام وصالة بمساحة (• (Y) اللوحدة وكل

$$
\text { وحدتين منقابلتين منماثلتين (شكل رقم } 7) .
$$

إجتماعياً: ركز البحث على الطبقة الإجتماعية لمحدودي الدخل و المستهدف تسكينهم بهذا النموذج وبنماذج الإسكان الإجتماعي الأخري بمجتمع المنيا كحالة دراسة إجتماعية ل ار اسة منطلباتهم الإجتماعية.

•. ب المنهجية التفصيلية لتحليل وتقييم حالة الدراسة Detailed Methodology of Analyzing and ) :(Evaluating Case Study

يعتمد تحليل وتقييم حالة الدراسة على معرفة مدى نو افر المتطلبات الاجتماعية من خلال ثلاثة محاور يمكن تحديدهم

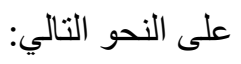

عدداً من حيث عدد الوحدات المنفذة والمستهدف تتفيذها بالمدينة، حيث أنه من المستهدف إنشاء عدد (ع • ب) بلوك سكني من هذا النموذج بإجمالي عدد وحدات سكنية يقدر بـ (YY و و حدة منتشرة في تجمعات عمر انية منفصلة منشابهة في تصميم الموقع العام وطريقة ترتيب الكتل بالموقع وتتركز في منطقة الإمتداد. تم إختيار التجمع العمر اني الوحيد من هذا النموذج الذي تم الانتهاء من إنشائه وتشطيبه وتم تسليمه للسكان وبه نسبة إنغال منو اضعة لحداثته، وذللك لتطبيق الدراسة عليه. يقع هذا التجمع بمنطقة الإمتداد (شكل رقم ؟) ويحتوي على عدد ( (0) بلوك سكني موزعة علي الموقع العام ومتلاصقة بالأطراف كل ثلاث بلوكات مجمعة حول فناء خارجي (شكل رقم 0). وكل بلوك سكني عبارة عن كتلة ضخمة مكونه من عدد (T) أدوار ومحتوية على عدد أربع وحدات سكنية بالدور الواحد، وكل وحدة مكونة من عدد (r)

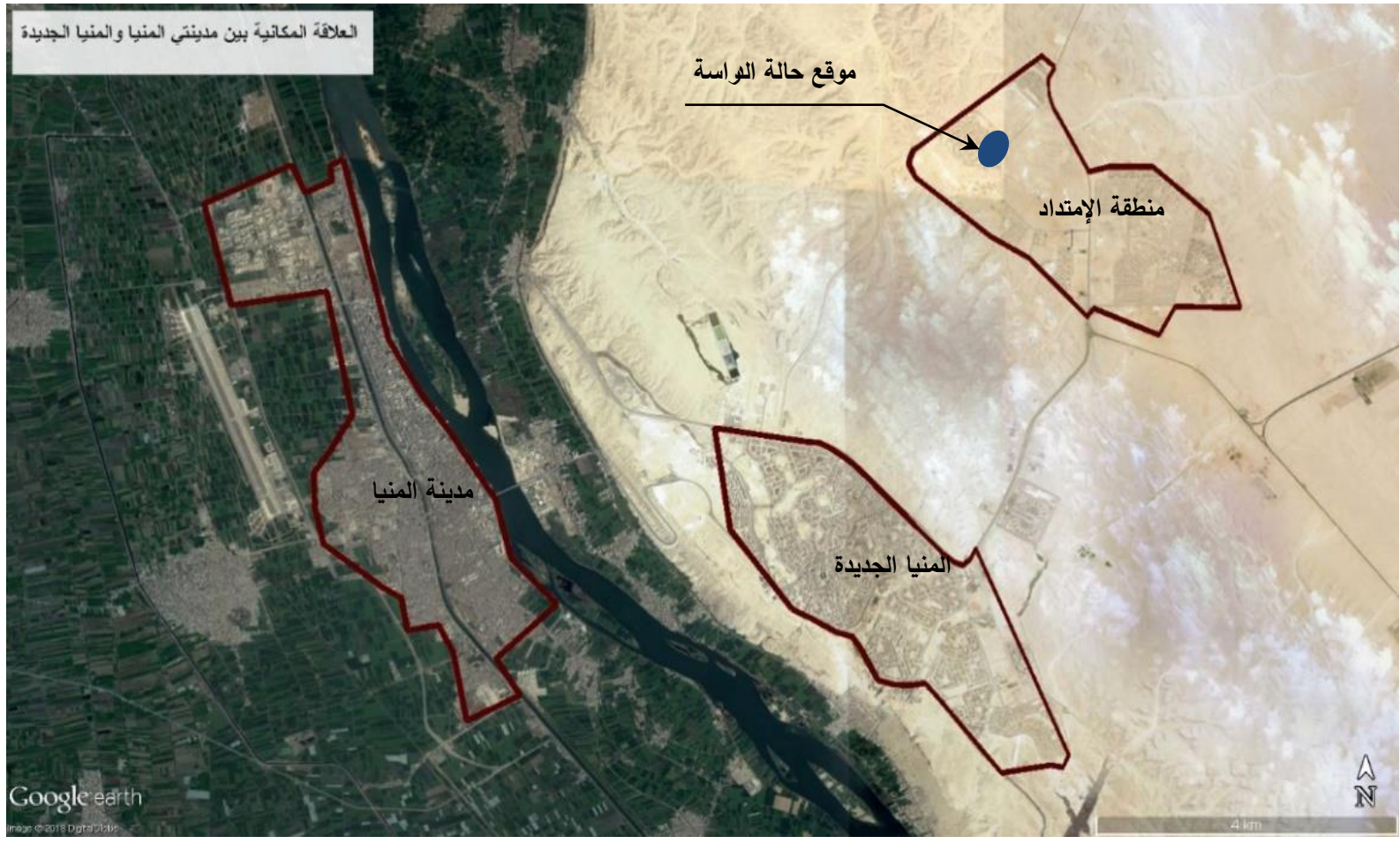

شكل (\&) ): العلاقة المكانية بين مدينتي المنيا القائمة والمنيا الجديدة وموقع حالة الدراسة [المصدر: Google earth بتصرف من الباحث] 


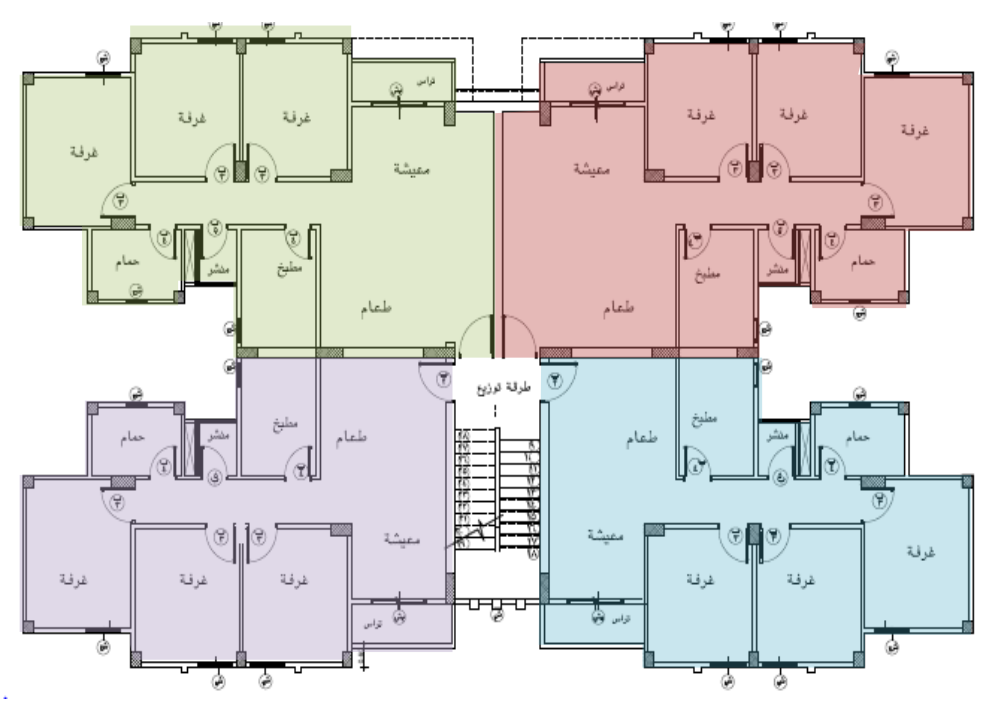

شكل (ך): المسقط الأفقي للاور المتكرر لنموذج حالة الدراسة [الباحث]

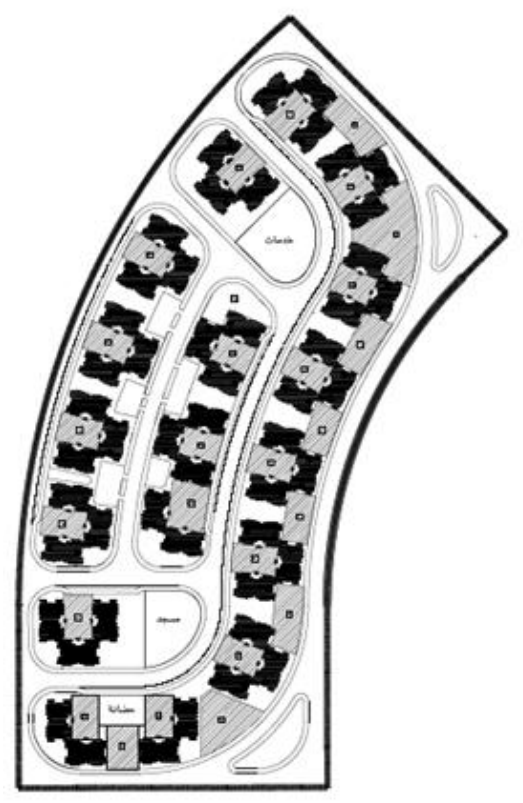

شكل (•): الموقع العام لحالة الدراسة [الباحث]
• الملاحظة والتصوير (Observation): نظر اً لحداثة تسليم حالة الدر اسة ونسبة الإشغال الضعيفة بها، مما لم يعط السكان الفرصة و الوقت لمحاولة إدخال تعديلات على تصميم وحداتهم السكنية، فقد نم تنفيذ هذا الجزء من الدراسة الميدانية علي نماذج الإسكان الإجتماعي الأخري الموجودة بالمدينة و المسكونة منذ فترة طويلة بنفس الثرائح الإجتماعية المستهدفة بالمشروع محل الدر اسة بهذا البحث. تم إستخدام طريقة الملاحظة لرصد التغيرات و التعديلات التى إجى قام بها السكان لوحداتهم السكنية بتلك المشروعات المأهولة نتيجة قصور تصميم تللك النماذج في تحقيق أحد متطلباتهم الإجتماعية من وجهة نظر هم ونتيجة لمعايثتهم وإستخدامهم لوحداتهم السكنية حتى تلائم إحتباجاتهم الإجتماعية، مع توثيق تلك التعديلات بالصور الفوتوغر افية. كذلك تم سؤ ال القائمين

$$
\text { بالتعديلات بطريقة المقابلة الثخصية بسؤ ال و احد مفتوح }
$$

• التحليل النظري (Theoretical Analysis): في ضوء المعايير المعمارية لتحقيق المنطلبات الإجتماعية المستخلصة من الدر اسة النظرية سالفة الذكر ، تم تحليل حالة الدراسة من مستوي الموقع العام وحتى التصميم الداخلي للنموذج بهدف الوقوف على مدي توفر تلك المعايير وبالتالي تحقيقها للمنطلب المنشود ومدي وملاءمتها نظرياً للإحتياجات الإجتماعية الإنسانية. إستخدم هذا التحليل طريقة مقارنة مقاييس وتواجد المعايير التصميمية لتحقيق المتطلب بحالة الدراسة، برورة تواجد المعيار التصميمي ومقاييسه

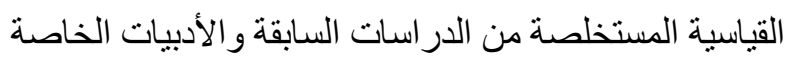
بالموضو ع، وذللك لتحديد أوجه نجاح تصميم حالة الدر اسة في تحقيق المتطلبات الإجتماعية لساكنيها ورصد أوجه القصور بها. 


\section{Journal of Advanced Engineering Trends (JAET), Vol. 38, No. 2. July}

تم تنفيذ الدراسة التطبيقية بإستخدام المقابلات الشخصية مع أفر اد عينة الدراسة بإعتبار ها أحد الوسائل التى يمكن إتباعها لجمع المعلومات و إستخدامها فى التوصل الى النتائج المطلوبة وخاصة أن بعض المنطلبات تحتاج لثرح ونوضيح من الباحث مما يجعل إستخدام الإستبيان غير مجدي، حيث تم وضع إستمارة مسبقة من الأسئلة والتي تشمل وضع إجابته علي مقياس من (1 : • 1 ) حيث 1 هو أقلهم أهمية و •1 هو أكثرهم أهمية، مع الاحتفاظ بقدر من المرونة مثل أن يقوم المجيب بتغطية نقطة قبل أخرى أو الخروج قليلاً عن موضوع السؤال لشر ح ر أيه وتوضيح وجهة نظره بشكل أكثر تفصيلاً

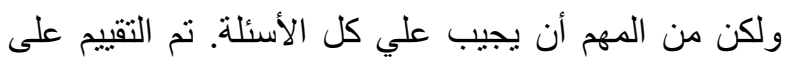
مستويين: - (2)

المستوي الأول: قياس أهمية كل متطلب من المتطلبات

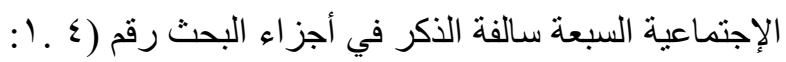
ع. V)، حيث فرض البحث أن مجموع أوزان ونسب أهمية وجود المتطلبات جميعها . ( ٪ ومن ثم تم وضع وزن نسبي لارجة أهمية كل متطلب كجزء من . . 1 من خلال إجابات المبحوثين وتقييمهم لأهمية المتطلب على المقياس العشري بالإستمارة المصممة. يوضح شكل رقم (V) طريقة حساب تللك الأوزان النسبية لأهمية المتطلبات الإجتماعية السبعة بالنسبة للطبقة الاجتماعية موضع الدر اسة والتي تمثل الأهمية القياسية لكل منطلب لتلك الطبقة والتي سوف يقارن بها نتائج المستوي الثاني من التقييم لبيان نسبة تحقق المتطلب في حالة الدر اسة. المستوي الثانسي: إعطاء وزن نسبي لأهمية وجود كل معيار تصميمي يحقق المنطلب الإجتماعي من المنطلبات السبعة سالفة التقييم بالمستوي الأول، حيث فرض البحث أن مجموع أوزان ونسب أهمية وجود المعايير التصميمية لتحقيق المنطلب الواحد جميعها تساوي الوزن النسبي للمنطلب المحسوب بالمستوي الأول ومن ثم تم وضع وزن نسبي لدرجة أهمية وجود كل معيار من خلال إجابات المبحوثين وتقييمهم لأهمية وجود المعيار التصميمي على المقياس العشري
"أماذا قمت بهذا التعديل؟"

للوقوف علي أهمية وجود المتطلبات الإجتماعية المختلفة من وجهة نظر تلك الثريحة الإجتماعية.

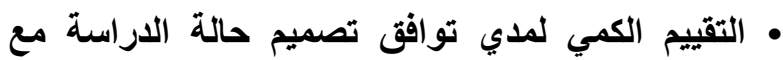
المتطلبات الإجتماعية للشريحة الإجتماعية التي تقطنها :(Quantitative Evaluation of Needs) لا يختلف أحد على أن المتطلبات الإجنماعية تحققها مهم للإنسان بوجه عام، إلا أن درجة أهمية تحقق كل متطلب تختلف بإختلاف الطبقة الإجتماعية للمبحوثين، كما إنها يمكن أن تختلف داخل الطبقة الإجتماعية الواحدة بإختلاف المكان وخصائص المجتمع المحيط. ومن المعروف أن سؤال المستخدم عن تللك المتطلبات وأهميتها بالنسبة له ستفرز بيانات ذو طبيعة نوعية (Qualitative data)، كان من الصعوبة التعبير عن تللك البيانات بصورة كمية يمكن قياسها حتى وقت قريب. مع (Quantitative data) تطور علوم الإحصاء العددي وظهور بعض المنهجيات بالعلوم الإجتماعية تتعامل مع البيانات النوعية مثل ( Fuzzy (Thematic و (Likert system) (logic [10 analysis)

$$
\text { بصورة رقمية كمية. }
$$

وقد إعتمد البحث في تقييم حالة الدر اسة على طريقة ( Likert (System و المبنية علي إعطاء وزن نسبي لهذه البيانات النوعية ومتغير اتها من خلال جعل المبحوثين يعبرون عن أر اءهم ودرجة أهمية كل متغير بالنسبة لهم علي مقياس رقمي ومن ثم بناء نموذج حسابي لنللك الآر اء. تم إختيار عينة الدراسة بشكل عشوائي متعمد من الطبقة الإجتماعية لمحدودي الدخل الساكنين بنموذج الإسكان الإجتماعي محل الدراسة ومن في نفس الطبقة الإجتماعية بنماذج الإسكان الإجتماعي الأخري بمجتمع المنيا، وكان حجم العينة ( • (^) مبحوث. 


\section{Journal of Advanced Engineering Trends (JAET), Vol. 38, No. 2. July}

الثاني وخصم الوزن النسبي للمعيار الغير موجود بالتصميم لنفس المتطلب، فناتج جمع الأوزان النسبية للمعايير المتوفرة المحققة لمتطلب و احد يعطي نسبة تحقيق هذا المتطلب في حالة الدراسة. وبالتالي يصبح مجموع نسب تحقق المتطلبات الاجتماعية فى نموذج حالة الدر اسة هو نسبة الرضى المتوقع أن يحصل عليها النموذج من قبل الساكنين من المنظور

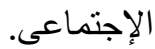

بالإستمارة المصممة. يوضح شكل رقم (^) طريقة حساب تلك الأوزان النسبية لأهمية وجود المعايير التصميمية المحققة للمتطلبات الإجتماعية، متخذة المتطلب A كمثال مع فرض وجود ץ معايير تصميمية تحققه. وينم تكرار هذا لكل

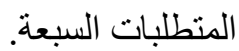
بتحليل تصميم حالة الدراسة و إعطاء كل معيار تصميمي محقق لمتطلب إجتماعي وزنه النسبي المحسوب بالمستوي

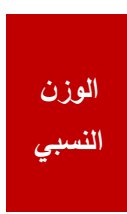

$\mathbf{A} \%$

\section{$\mathrm{B} \%$}

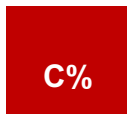

$\%$
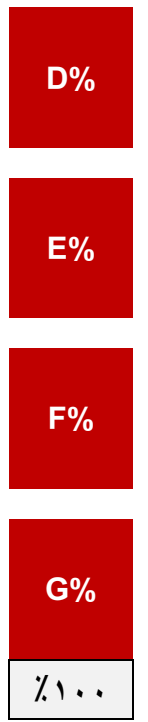
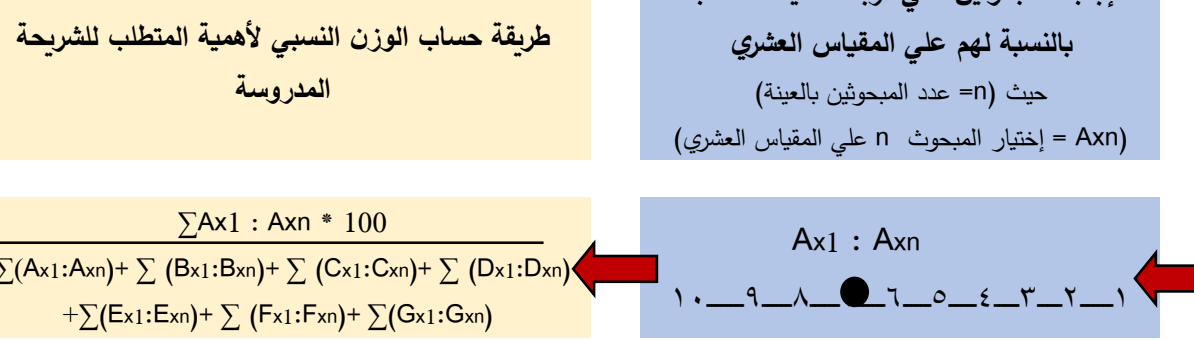

A

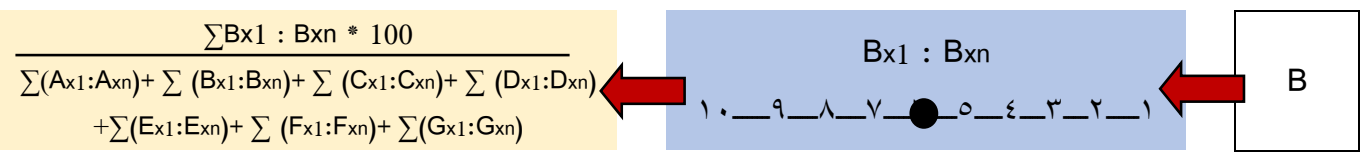

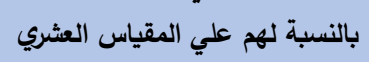

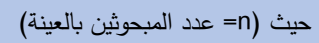

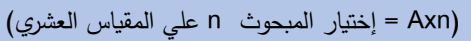

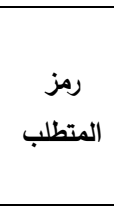

رقم المتطلب

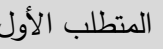

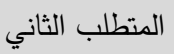
$+\sum\left(\mathrm{E}_{\mathrm{x} 1}: \mathrm{E}_{\mathrm{x} n}\right)+\sum\left(\mathrm{F}_{\mathrm{x} 1}: \mathrm{F}_{\mathrm{x} n}\right)+\sum\left(\mathrm{G}_{\mathrm{x} 1}: \mathrm{G}_{\mathrm{x} n}\right)$

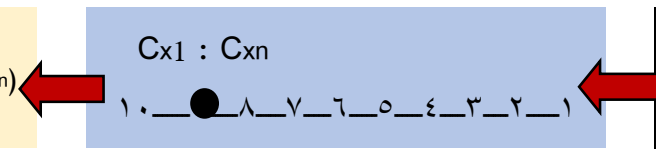

C

المتطلب الثالث $+\sum\left(E_{x 1}: E_{x n}\right)+\sum\left(F_{x 1}: F_{x n}\right)+\sum\left(G_{x 1}: G \times n\right)$

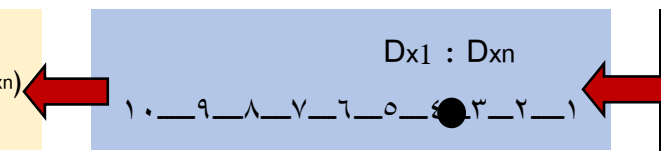

D

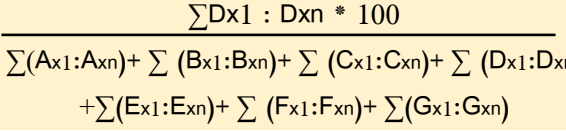
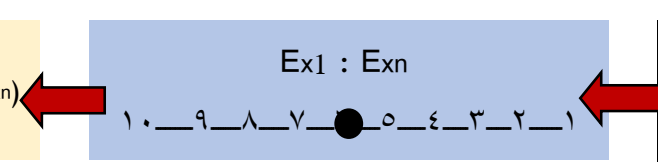

E

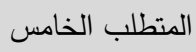
$+\sum\left(E_{x 1}: E_{x n}\right)+\sum\left(F_{x 1}: F_{x n}\right)+\sum\left(G_{x 1}: G_{x n}\right)$

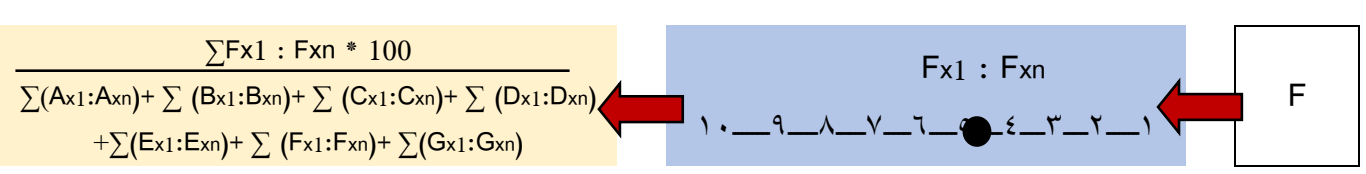

المتطلب السادس $+\sum\left(\mathrm{E}_{x 1}: \mathrm{E}_{x n}\right)+\sum\left(\mathrm{F}_{x 1}: \mathrm{F}_{x n}\right)+\sum\left(\mathrm{G}_{x 1}: \mathrm{G}_{x n}\right)$

Gx1 : Gxn

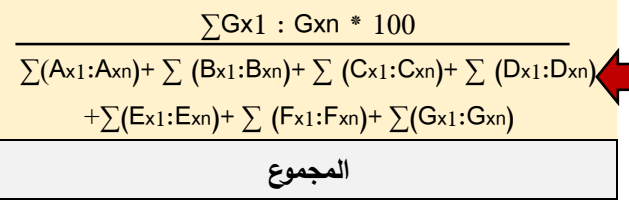
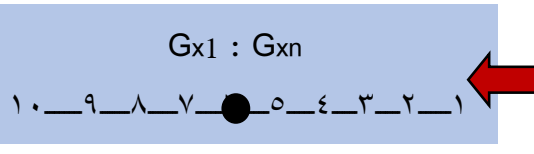

G

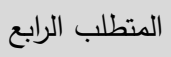

المنطلب السادس

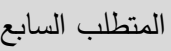

شكل (V): منهجية وطريقة حساب الأوزان النسبية لدرجة أهمية المتطلب من وجهة نظر عينة الدراسة 


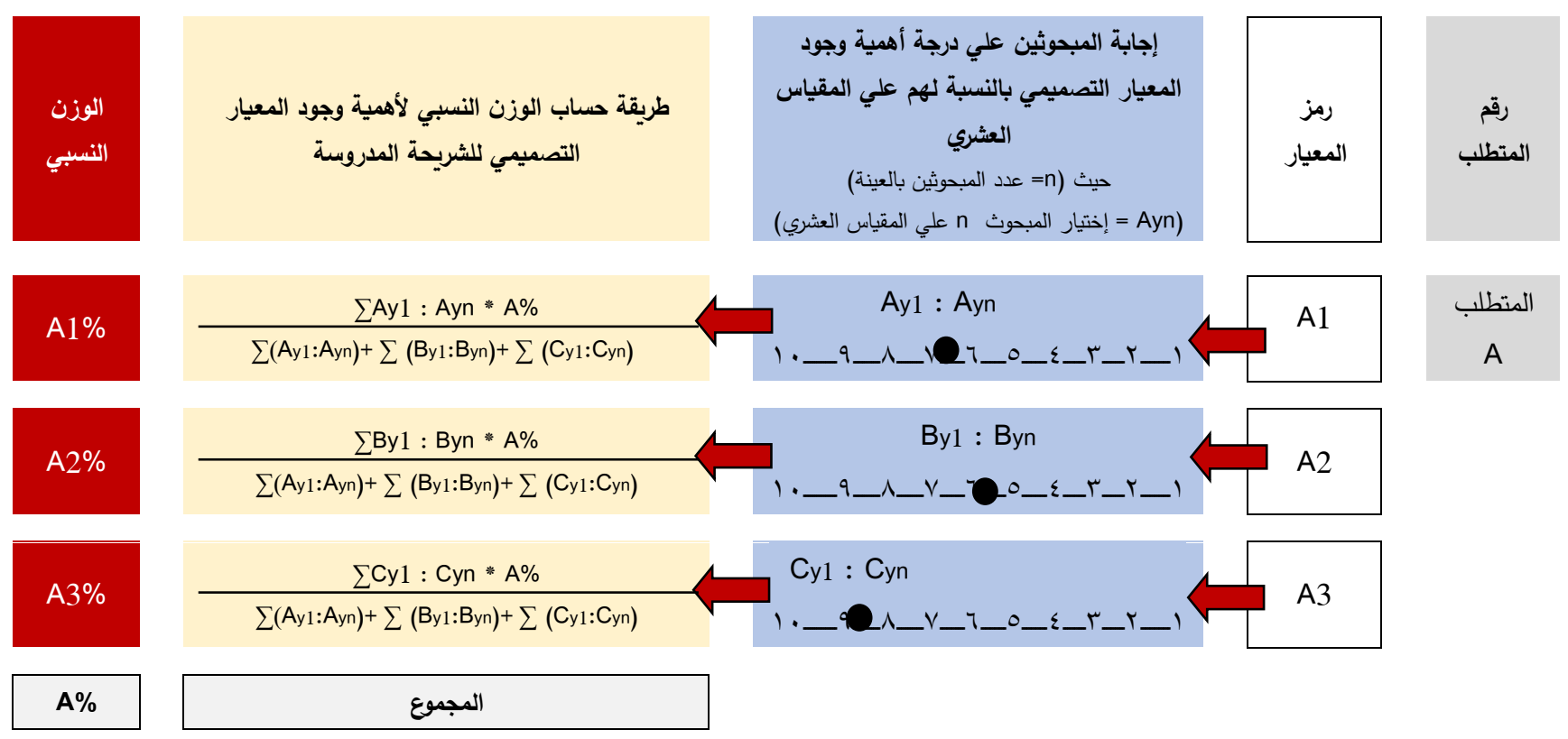

شكل (^): مثال لمنهجية وطريقة حساب الأوزان النسبية للرجة أهمية وجود المعايير التصميمية المحقةة للمنطبات التصميمية من وجهة نظر عينة الاراسة

أربعة أماكن لإنتظار السيارات بإجمالي سعة (• ع ) سبارة (نكل رقم · ( ))، وجود خمسة أماكن إنتظار للسيار ات بالقرب من المبانى السكنية يزيد من حدة الضوضاء كما أنه لا يوجد سياج من الاشجار حول تللك الأماكن لتقليل حدة الضوضاء

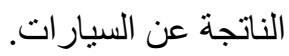

• علاقة الفراغات السكنية بشبكة الشوارع وممرات المشاة: لوحظ أن جميع الفراغات السكنية الموجودة بالموقع تتصل بشكل مباشر بالمرور الآلي ولا يفصلها عنه إلا رصيف

$$
\text { عرضه ب منر (شكل رقم 9). }
$$

• علاقة الكتل بالكتل المجاورة فى الموقع العام: تم بناء الكتل بشكل شبه متصل من جانب واحد او جانبين ويعتبر الوضع الاكثر شيو عا فى الموقع العام هو الكتلة شبه المتصلة مع كتلة اخرى من جانب واحد فقط ( بr كتلة) و هناك عدد 10 كتلة فقط شبه متصلة من جانبين (شكل رقم (1).
๑م ب نتائج التحليل النظري لحالة الدراسة ( Theoretical :(Analysis Results

جاءت نتائج التحليل النظري لحالة الدر اسة في ضوء المعايير التصميمية المحققة للمتطلبات الإجتماعية المستخلصة من الدر اسة النظرية على جميع المستويات التصميمية كما يلي:

\section{أـ الموقع العام:}

• المساحات المفتوحة: هناك عدد (YV) مساحة مفتوحة عامة فى الموقع ممثلة بأفنية خارجية تم بناء الكتل حولها، تتفق معظمها من حيث الثكل و المساحة و جميعها مخصصة للمشاة ومتصلة من جانب واحد بالمرور الآلي (شكل رقم 9)، وجود Tو T اغ سكنى تسعد على إثباع الحاجة الى الاتصال، ولكنها متصلة بالمرور الألى مما يجعلها غير آمنة.

• شبكة الشوارع وممرات المشاة: يخدم هذا الموقع شبكة مرور آلي يحدها رصيف عرضه ب مثر، اما ممرات المشاة فهي تتخلل الأفنية الخارجية بين البلوكات السكنية مع وجود - 197 - 


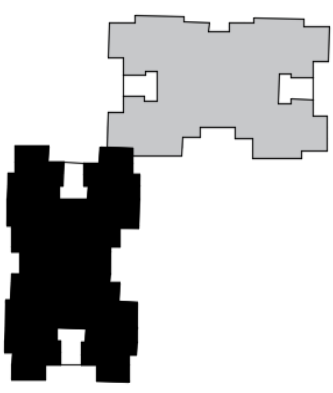

كثلة متصلة من جمة واحدة

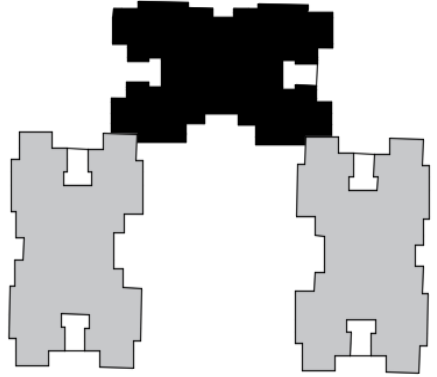

كتلة متصلة من جمتين

شكل (1 (1): نسق اتصال الكتل البنائية ببعضها بالموقع [المصدر: الباحث]

• المسافات بين الكتل فى الموقع العام: أقل مسافة بين

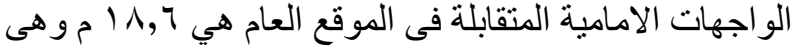
مسافة تحقق الخصوصية وأقل مسافة بين الواجهات الجانبية المتقابلة هي ب ا متر وهى مسافة تحقق الخصوصية، و أقل مسافة بين حو ائط المناور المتقابلة هي V ₹ , Y م و هیى مسافة لا تحقق الخصوصية (شكل رقم r I).

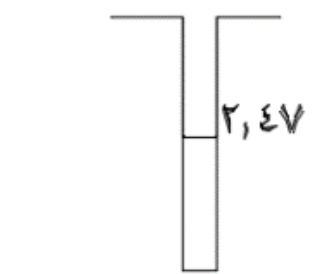

العساقة بين حواهل العناور الداخلية

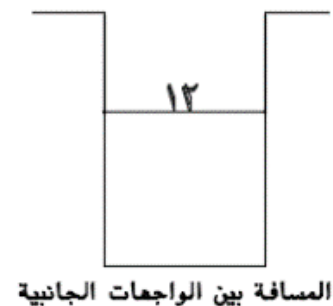

شكل (r 1 ): المسافات الدنيا بين الواجهات بالموقع العام [المصد: الباحث]

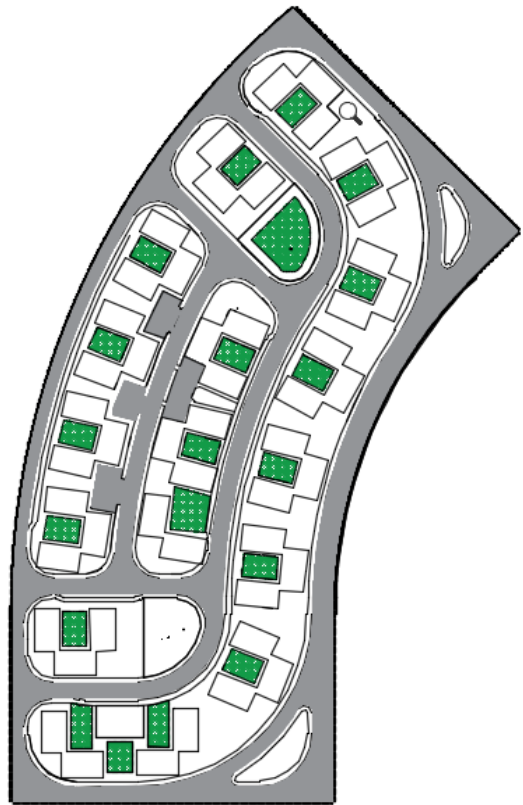

شكل (9): الأفنية الخارجية وتوزيع الكتل حولها [المصدر: الباحث]

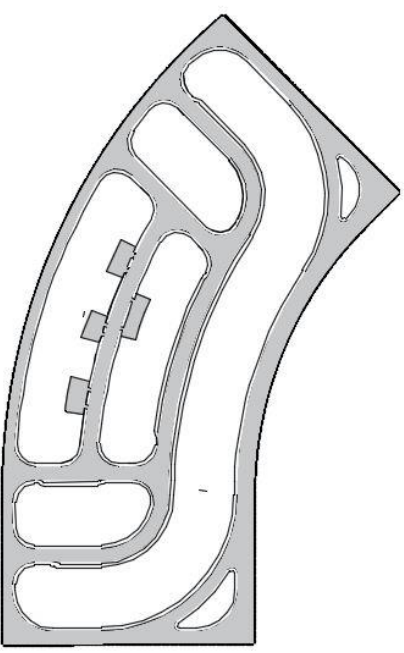

شكل ( • 1): شبكة المرور الآلي بالموقع العام [المصد: الباحث] 


\section{ج- التصديم اللد/خلمى للمبنحي:}

من خلال تحليل التصميم الداخلى للوحدة السكنية تم ملاحظة ما يلى:-

• سمك الحوائط المشتركة مع الجيران مبسم مما يحقق

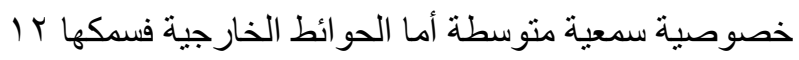
سم مما يساعد على إنتقال الضوضاء من الخارج الى الداخل (شكل رقم 7 ( ).

• الوحدات السكنية كاملة التشطيب كدهانات وأرضيات مما لا يتيح للسكان إبداء أراءهم وتحقيق تطلعاتهم و إظهار شخصيتهم من حيث التدخل فى إختيار ألوان التشطيبات و أنو اعها.

• الشبابيك الخارجية عبارة عن شبابيك زجاجية مزودة بشيش خشبي. • أبواب البلكونات عبارة عن أبواب ألومنيوم زجاج أبيض

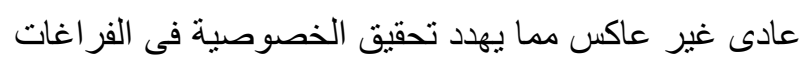

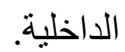

• أبواب البلكونات و الثبابيك بالدور الأرضي مزودة بحديد

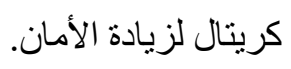

• مساحات الفر اغات السكنية بالوحدات السكنية هي كالتالي

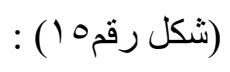

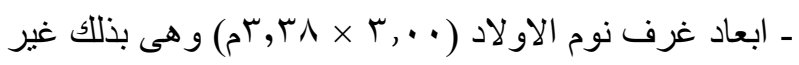
مناسبة لتلبية احتياجات النوم و المذاكرة حيث أن طبقة محدود لوني الدخل غالباً ما تستخدم الفراغ فى أكثر من غرض وض وغالباً ما تدمج فراغ المذاكرة مع فر اغ النوم فى غرفة واحدة وحيث ان

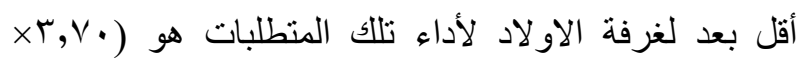

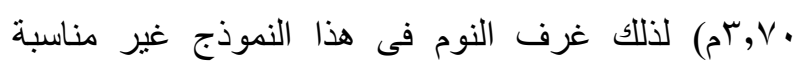

وظيفياً.
• عناصر فرش المساحات المفتوحة: تم تهيئة الفراغات و المساحات المفتوحة بعناصر الجلوس والانتظار كما هو

موضح بالثكل رقم (T (1).

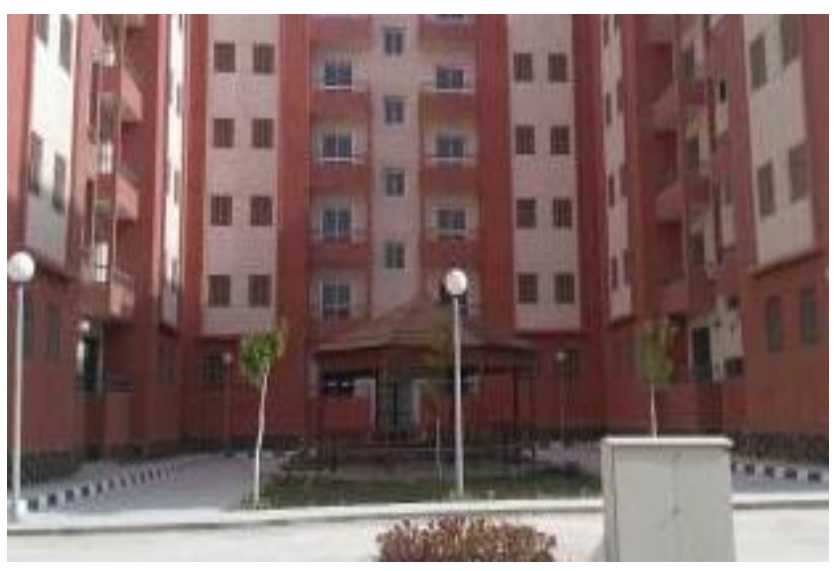

شكل (r 1 ): تهيئة المساحات المفتوحة للجلوس والانتظار بموقع حالة الاراسة

ب- كتلة المبنحي:

كتلة المبنى عبارة عن كتلة ضخمة مكونة من ستة طوابق

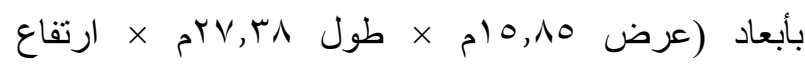

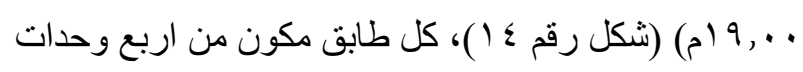
سكنية كل وحدة سكنية تتكون من ثلاثة غرف وصالة استقبال

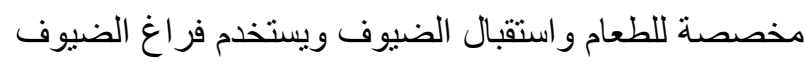
كفر اغ معيشة أيضاً ومطبخ وحمام كما هو موضح بالثكل رقم

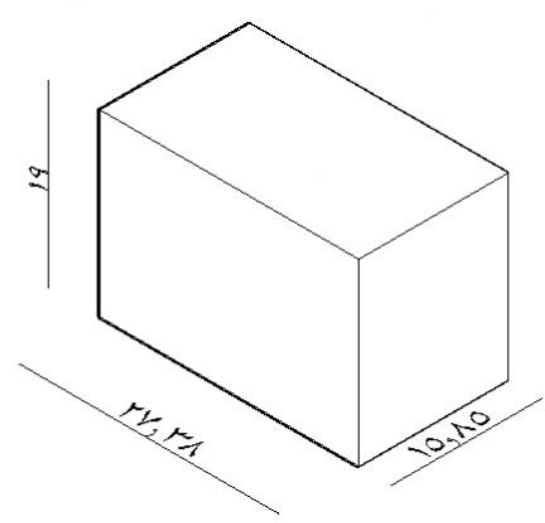

شكل (ع 1): كتلة المبني وأبعادها [المصدر: الباحث] 


\section{Journal of Advanced Engineering Trends (JAET), Vol. 38, No. 2. July}

ا - تم تزويد ابو اب الوحدات السكنية الخارجية بأبو اب حديدية مما يؤكد على رغبة السكان فى زيادة الامان أو الحماية كما هو موضح بالثكل المرفق رقم (1 1 ـ أ) r- تم تركيب حديد حماية لبلكونات الدور الأرضي من الخارج وذلك لزيادة الحماية والامان ايضاء كما بالشكل

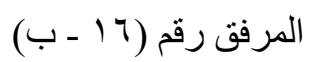

r- تم عمل ستائر على البلكونات من الخارج وذللك للحماية من أثُعة الثمس وكذلك زيادة الخصوصية كما بالثكل

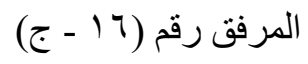

ع- ت تم تقفيل كوبستات البلكونات بشبابيك زجاجية أو خشبية وذللك لإضافتها لمساحة الصالة لكي تكفى إحتياجاتهم من المساحة اللازمة للطعام و المعيشة و إستقبال الضيوف كما

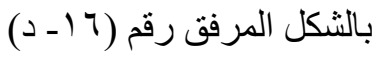

ــ ـ تم تغطية الجزء الر أسي المكشوف من كوبستة البلكونة وذللك لتحقيق الخصوصية كما بالثكل المرفق رقم ( 17 ـ

7- تم إستغلال جزء من الملكية العامة كملكية خاصة وذلك لعمل جراجات للدرجات البخارية وغير ها وذلك لعدم وجود مكان آمن يسمح بإستخدامه كجراج للاراجات

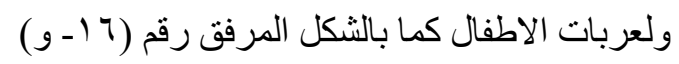
V- ت تم تعديل جزء من السلالم كمنحدر ولذلك لاستخدامها لذوى الاحتياجات الخاصة و استخدامها فى حركة عربات

$$
\text { الاطفال كما بالثكل المرفق رقم (7 } 1 \text { - ز ز) }
$$

A- تم تركيب بو ابات حديدية على مداخل العمارات السكنية وذللك لأن العمار ات السكنية فى كثير من النماذج السكنية لا تحتوى على باب مدخل مما دفع السكان لإضـافته لزيادة

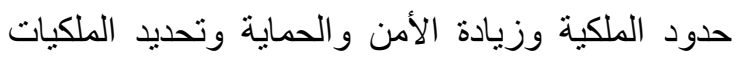

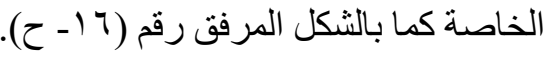

ـ أبعاد غرفة نوم الزوجين ( . . غير مناسبة حيث ان أقل مساحة مناسبة للفرش المتعارف عليه

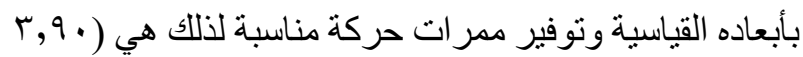

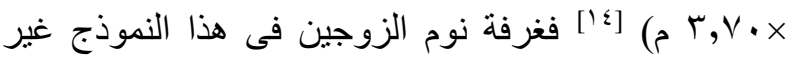

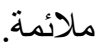

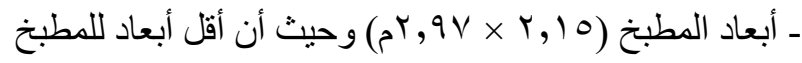
لأداء الوظيفة هى ( r, × × r, r م) لذللك فإنه يمكن اعتبار أن مساحة المطبخ مناسبة.

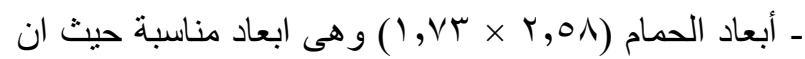
أقل مساحة لأداء الوظيفة المطلوب هى ( • Y, (م × • ع, Y م). ـ أبعاد صالة المعيشة والطعام وحيث أنها تستخدم لإستقبال الضيوف أيضا لعدم وجود فر اغ لإستقبال الضيوف فأبعاد هذا الفر اغ غير مناسبة.

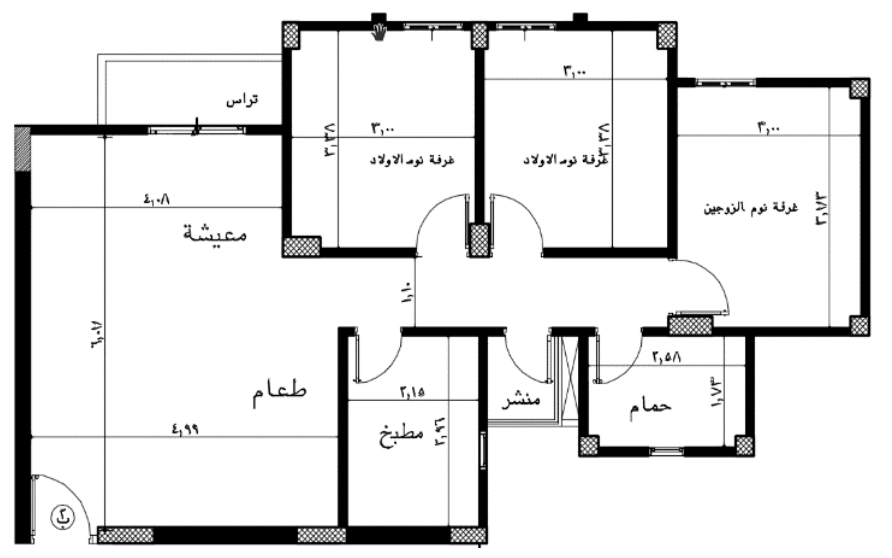

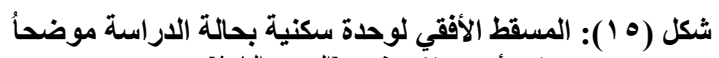

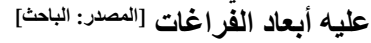

๑. ؛ نتائج الملاحظة والتصوير (Observation Results): من خلال المتابعة الميدانية لمو اقع الإسكان الإجتماعي المختلفة التى أقيمت فى المنيا الجديدة ومتابعة التغير ات والتعديلات التى قام بها السكان بالوحدات السكنية بها فقد تم ملاحظة الآتى: 

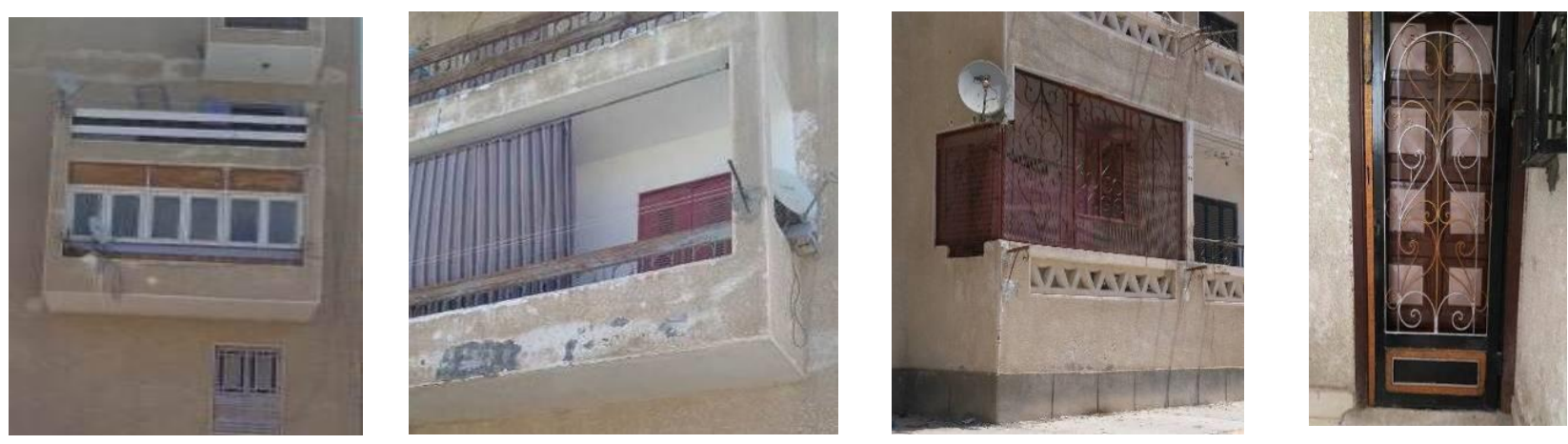

$$
\text { (د) تقفيل البلكونة بشباك خثبى او }
$$

$$
\text { (ج) تركيب ستائر على البلكونات من الخارج }
$$

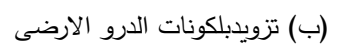

بشبكة حديدية

$$
\text { (أ) إضافة ابواب حديدية }
$$
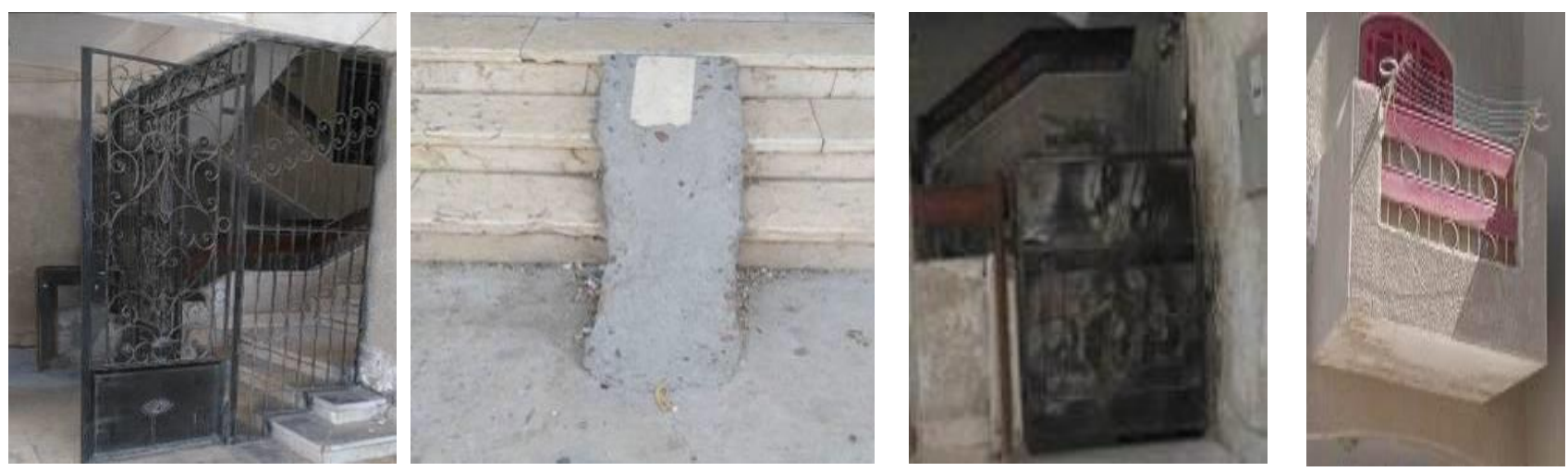

بأبواب حديدية ابواب العمارات السكنية
بابية

(j) تعديل جزء من السلم كمنحدر

(و) إستغلال جزء من الملكية العامة

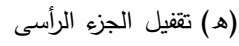

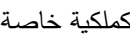

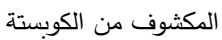

شكل (7 1): التعديلات التى قام بها السكان على وحداتهم السكنية [المصدر: الباحث]

أولاً: تقييم ونسب اهمية وجود المتطبات الاجتماعية فى من المباني السكنية من وجهة نظر المستهذف تسكينهم:

- إحتل مطلب الحاجة الى الوظيفية النسبة الأكبر والدرجة الأولى من حيث الأهمية فى الحصول على رضى المستخدمين عن تصميم الوحدة السكنية أو المبنى السكنى من الناحية

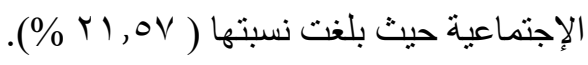

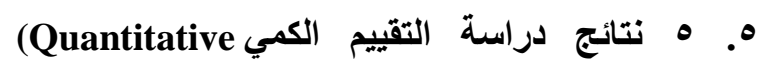
Evaluation Study Results)

جاءت نتائج التقييم الكمي لمدي تو افق تصميم حالة الدراسة مع المتطلبات الإجتماعية للشريحة الإجتماعية التي تقطنها بتطبيق المنهجية التفصيلية سالفة الذكر بمستوييها كما تلي مناقثته. 
Vol. 40, No. 1. January 2021

ثانياً: تقييم المعايير المعمارية الواجب توافرها فى المبنى السكنى من وجهة نظر المستهرف تسكينهم:

فمن خلال تقييم السكان او المستهف إسكانهم أمكن استتناج

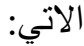

نسبة تحقق المتطلب نسبة الى المتطلبات الاجتماعية ككل = نسبة تحقق المتطلب × نسبة المتطلب بالنسبة للمنطلبات ككل. • نسبة تحقق الخصوصية فى نموذج حالة الدراسة الى

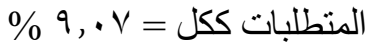

• نسبة تحقق منطلب الحاجة الى الاتصال فى نموذج حالة الدر اسة الى المتطلبات ككل = • ب, 0 \%

• نسبة تحقق متطلب الإحتواء فى نموذج حالة الدراسة الى

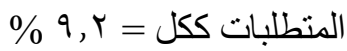

• نسبة تحقق متطلب الحماية فى نموذج حالة الدراسة الى المتطلبات ككل = 99 , 9 \%

• نسبة تحقق منطلب الوظيفية فى نموذج حالة الدراسة الى الى المتطلبات ككل ب, • •1 \%

• نسبة تحقق متطلب الحدود و الملكية وتحقيق الثخصية الى المتطلبات ككل = r r r

• نسبة تحقق منطلب الرمزية نسبة الى المتطلبات الاجتماعية ككل = صفر \% \%

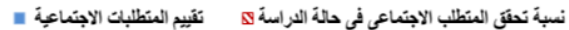

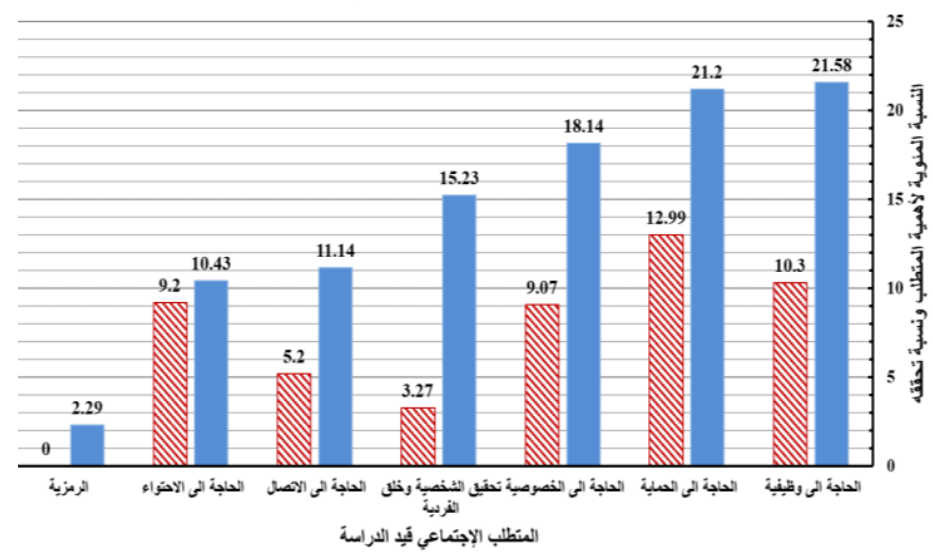

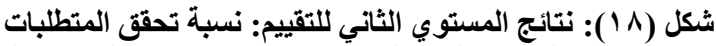

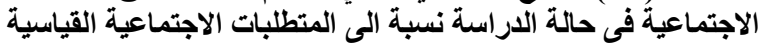
الناتجة من المستوي الأول للتقييم [المصدر: الباحث]
ـ إحتل مطلب الحاجة الى الحماية الدرجة الثانية من حيث الأهمية بفارق بسيط عن الوظيفة حيث بلغت نسبتها ( , , Y \%). - إحتل مطلب الحاجة الى الخصوصية الدرجة الثالثة من حيث

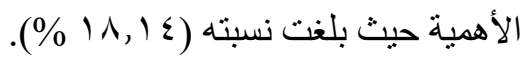
- إحتل مطلب الملكية والحدود وتحقيق الثخصية الأهمية بالتتابع حيث بلغت نسبته (ب, 10 10\%) أما الحاجة للاتصال

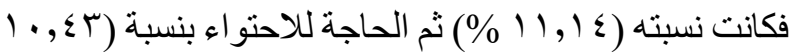
\%) وجاء فى المركز الاخير الحاجة الى الرمزية بنسبة

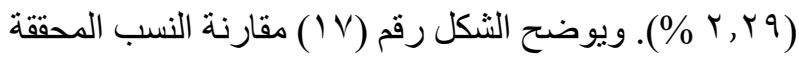
فى كل مطلب من تللك المطالب.

لعب سهولة أو صعوبة التعامل مع عدم وجود المتطلب أو القصور فيه دور كبير لدي المبحوثين فى إعطاء نسبة أقل أو أكبر فى أهمية وجوده لديهم. كما كان للظروف الر اهنة عقب

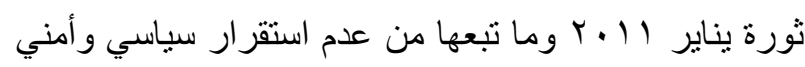
و عدم إحساس المبحوثين بالحماية وبالأمن و الأمان كوضع عام دور أيضاً فى تكوين وجهة نظر هم. لوحظ أيضاً عدم اكتر اث نسبة كبيرة من المبحوثين لتكوين علاقات إجتماعية فيما بينهم وجير انهم و عللوا ذللك بالظروف الاقتصادية التى تعيشها تللك الطبقة و عدم وجود وقت كافي للاهنمام بتكوين تللك العلاقات.

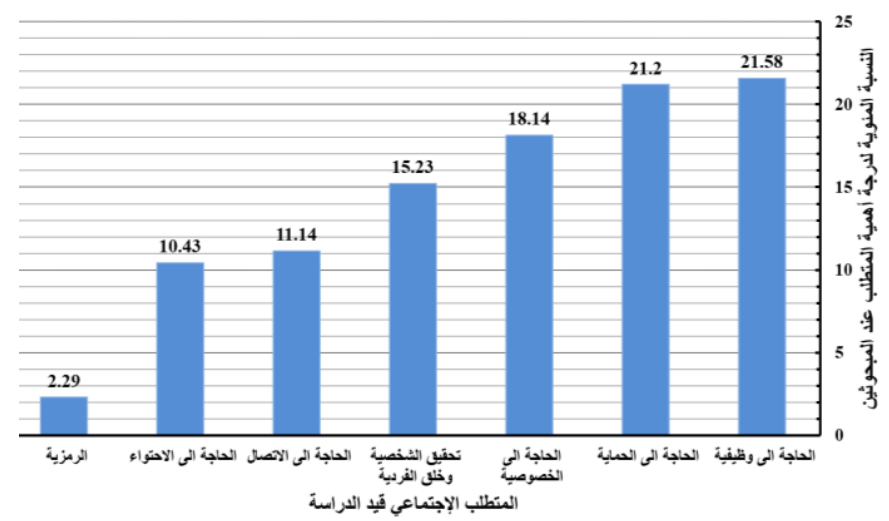

شكل (V V ) : نتائج المستوي الأول للتقييم: تقييم أهمية المتطلبات الإجتماعية طبقاً لر أى المستويته الاول تسكينهم [المصدر: الباحث] 


\section{Vol. 40, No. 1. January 2021}

• الوزن النسبي الذي أعطاه المبحوثين لبعض الإحتياجات التي تم در استها جاء معبر اً عن ترتيب أهمية الإحتياج بالنسبة لهم

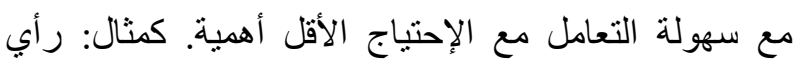
المبحوثين أن تحقيق إحتياج الوظيفية أهم كثيراً من تحقيق الخصوصية فهم يمكنهم تحقيق قدر من الخصوصية بإستخدام بعض الوسائل البسيطة قليلة التكلفة.

• هنالك تناقض بين اهمية وجود بعض المعايير المعمارية نظرياًُ اهمية وجود تلك المعايير عند المستخدم المبحوث كأهمية وجود صالة المدخل و اهمية بعد مداخل العمار ات عن

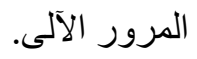

• إغفال بعض المعايير الهامة لدي السكان بالتصميم يدفعهم الى التدخل بالتعديل لتوفير إحتياجه بنفسه مما ينتج عنه تشويه بالواجهات فى بعض الاحيان والتعدي على حقوق الغير فى

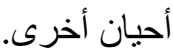

• أمكن التوصل الى تحديد نسبة تحقق المنطلبات الاجتماعبة فى حالة الدراسة من خلال الوزن النسبي الذى أعطته هذه الثريحة الاجتماعية قيد الدر اسة لتكون ؟ , • \% ـ ـ

• ومن خلال هذه النتيجة يمكن الحكم بأن نماذج الاسكان المستهدف توطين شريحة محدودي الدخل بها غير ملائمة للاحتباجات الاجتماعية للسكان. • أثنتت نتائج الدراسة الكمية صلاحية المنهجية والنموذج الرياضي المقترح كأداه للتقييم الكمي بموستو ييه ودقة قياساته. 7. Y التوصيات العامة للبحث:-توصل البحث الى مجموعة من التوصيات يمكن تحديد أهمها فيما يلى:
وبناءا على ذللك فإن نسبة تحقق المنطلبات الاجتماعية فى نموذج حالة الدر اسة = مجموع نسب تحقق جميع المتطلبات = نسبة تحقق الوظيفية + نسبة تحقق الحماية + نسبة تحقق الخصوصية + نسبة تحقق الثخصية وخلق الفردية + نسبة تحقق الاتصال + نسبة تحقق الاحتو اء + نسبة تحقق الرمزية $+q, r+0, r \cdot+r, r v+q, \cdot v+r, q 9+1 \cdot r \cdot r \cdot=$

$$
\% 0^{\circ}, r=\cdot, \cdot \cdot
$$

\section{7. النتائج والتوصيات (Results and Recommendations):} 7 ا 1 النتائج العامة للبحث: نوصل البحث الى مجمو عة من النتائج يمكن تحديد أهمها فيما يلى اليح:

• يجب أن يكون المسكن الملائم مشبعاً لاحتياجات المستخدم المختلفة وبالتالي يجب أن تتو افر فيه المنطلبات الاجتماعية فى لئ

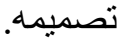
• يجب أن تفي مساحات الفر اغات السكنية بالوظيفة التى أنشئت

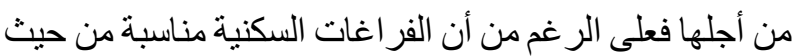
العدد إلا ان مساحتها غير مناسبة للفرش والحركة بحالة

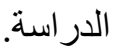
• افتقاد الصلة بين المصمم والمستخدم حيث تتم العملية التصميمية وكذللك التنفيذية من البداية حتى الوصول الى التشطيبات النهائية دون معرفة رغبات السكان و احتياجاتهم، أو مشاركتهم فى إختيار انواع والوان التشطيبات الداخلية

$$
\text { لوحداتهم السكنية. }
$$

• تم إغفال بعض المعايير الواجب نو افرها رغم أهميتها لدى السكان منها توفير منطقة لعب آمنة للأطفال تكون مر اقبة من قبل السكان، وتوفير مكان آمن لإنتظار وسائل الانتقال البسيطة كالدر اجات و عربات الاطفال حيث أن الفئة المستهدفة من هذه الوحدات السكنية بها نسبة إمتلاك سيار ات ضعيفة جداً. 


\section{Vol. 40, No. 1. January 2021}

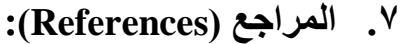

['] دينا ممدوح محمود نصار. در اسة تفصيلية للر احة الحسية البصرية

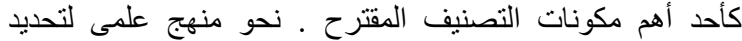

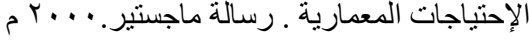

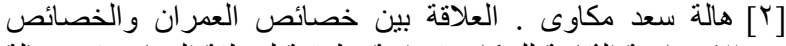
الإجتماعية الثقافية للسكان (دراسة تطبيقية لمنطقة المعادى ) رلئ رسالة

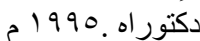

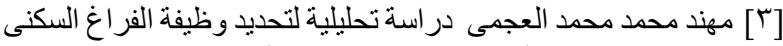

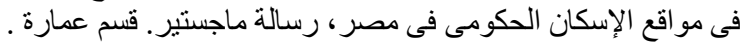

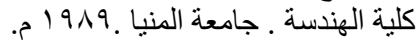

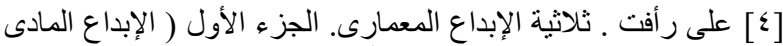

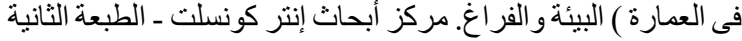
r...r.

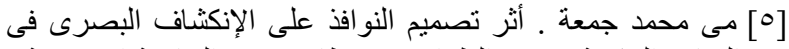

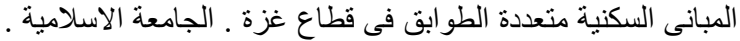

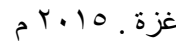

[7] عصام رجب إسماعيل . مفهوم الخصوصية وتأثيره على تصميم

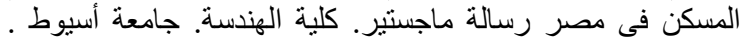
م 1998

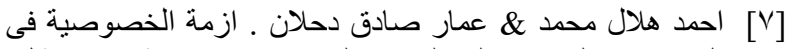

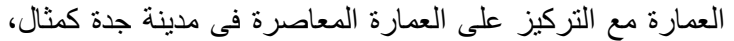

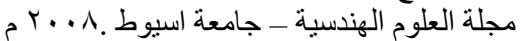

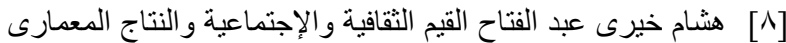

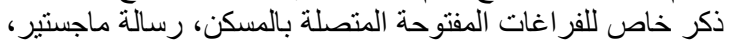

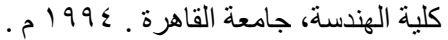

[9] باهر إسماعيل فرحات. العلاقة التبادلية بين السلوك الإنسانى و البيئة

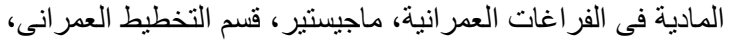

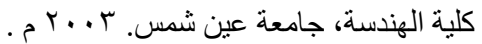

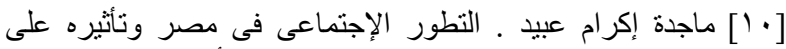

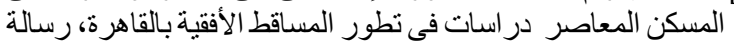

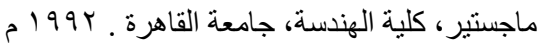

[11] الزواوى بغورة الثقافة بين التقليد والتجديد ، مجلة الكويت ، العدد . r.0.70

Abrams, Charles (1964): Housing in modern world- [ 1 Y $]$ London - faber and faber P 18

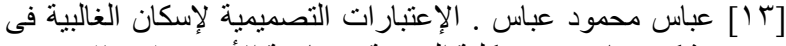

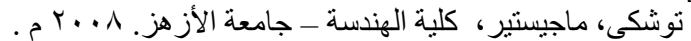

Boon, H. and Deborah, B. (2012) Analyzing [ [ $]$ Likert data. Journal of Extension, 50(2).

Braun, V. and Clarke, V. (2006) Using thematic [10] analysis in psychology. Qualitative Research in

Psychology, 3 (2). pp. 77-101.
• يوصى البحث بأهمبة تحقيق وتفعيل المشاركة المجتمعية للسكان فى اتخاذ القرار ات الخاصة بنماذج الاسكان لمعرفة متطلباتهم المختلفة التى يفرضها المجتمع المنتمين البه. • ضرورة التوصل الى تصميم المسكن الملائم والمحقق لاحتياجات المتطلبات الاجتماعية المختلفة.

• ضرورة ملائمة المساحات الوظيفية لجميع الفر اغات السكنية

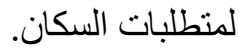
• ضرورة تقوية الصلة بين فكر المصمم ورغبات المستخدم من البداية حتى الوصول الى التشطيبات النهائية بما بحقق رغبات السكان و احتياجاتهم.

• عدم إغفال كافة المعايير التصميمية التى يتطلبها السكان طبقا لفئاتهم الاجتماعية المختلفة، لضمان عدم تذخلهم بالتعديل لتوفير إحتياجاتهم بأنفسهم.

• ضرورة الاهتمام بتحقق المتطلبات الاجتماعية للسكان حيث أثبتت الدر اسة أنه تحنل نسبة هامة من متطلباتهم.

• ضرورة توفير المتطلبات الإجتماعية المختلفة بحسب أهميتها التى تم التوصل البها بالدراسة البحثية والتي جاءت حسب ثرتيب أهميتها كمتطلبات بدأت بالوظيفية ثم الحماية ثم الخصوصية ثم الملكية و الحدود وتحقيق الشخصية ثم الاتصسال ثم الاحتو اء ثم الرمزية على الترتيب بالنسبة للطبقة الاجتماعية المبحوثة. • إستخدام المنهجية و النموذج الرياضي المقترح بالبحث من ثبل المصدم في المر احل الأولي للتصميم سيساعد بشكل كبير في خروج التصميم بشكل منوافق مع إحتياجات الطبقة الاجتماعية المستهدفة للتسكين بالمشروع بشكل كبير حيث أن النتائج ستختلف بشكل كبير بتغير الطبقة الاجتماعية المبحوثة. 